\title{
TITLE
}

\section{Urban services, pedestrian networks and behaviors to measure elderly accessibility}

\author{
Author: Federica Gaglione ${ }^{\text {a }}$, Caitlin Cottrill $^{\mathbf{b}}$, Carmela Gargiulo ${ }^{\mathrm{a}}$ \\ ${ }^{a}$ University of Naples Federico II - Department of Civil, Architectural and Environmental Engineering, Italy \\ ${ }^{b}$ University of Aberdeen- School of Engineering, United Kingdom
}

\begin{abstract}
Relationships between the organisation of the pedestrian network and the location and distribution of activities represent an important element in improving accessibility to urban services of interest to the elderly. This paper proposes a methodology aimed at defining a new measure of pedestrian accessibility for elderly. We first identify characteristics of the pedestrian network and built environment that may impact upon accessibility to elderly, and weight each feature using an AHP analysis. Walking behaviours are considered in terms of walking speed and travel times for elderly. Accessibility levels are derived referring to the system defined by the relationship between the characteristics of the pedestrian network, the offer of urban services and behaviours of elderly. This methodology has been tested in the urban contexts of Naples and Aberdeen. The results provide useful suggestions to decision makers in prioritising interventions to be implemented at the neighbourhood scale to improve the accessibility to urban services.
\end{abstract}

Keywords: elderly; pedestrian networks; urban accessibility; Analytic Hierarchy Process; GIS 


\section{INTRODUCTION}

Population ageing is one of the great social and economic challenges for Organisation for Economic Cooperation and Development (OECD) countries. Scientific and technological advances, combined with economic development, have favoured an increase in life expectancy and consequently a decline in mortality. However, if, on the one hand, longevity is in itself an achievement due to advances in medicine, on the other hand, this demographic trend has numerous implications in economic, social security, welfare and urban terms. The United Nations Population Fund predicts that the world population is expected to reach 9.7 billion people in 2050, of which $22 \%$ will be over 60 years old and $33 \%$ will be living in developed countries. In particular, in some countries, such as China, India and the United States, the number of people aged 60 or older is over 100 million.

This ongoing demographic trend has triggered a series of changes in the way cities develop, are managed and support the community. The World Health Organization has played a primary role in identifying the key elements necessary to create the conditions for "active ageing" long before one reaches old age. The "World report on ageing and health" (World Health Organization, 2015) emphasises the importance of adapting the built environment to the needs and requirements of older persons. In particular, it aims at replacing outdated policies that primarily consider elderly people as passive subjects with policies that recognise everyone's right and responsibility to play an active role and participate in community life at every stage of life, including old age. In this context, the WHO Global Network for Age-friendly Cities and Communities ${ }^{1}$ is a fundamental reference. It collects and shares experiences from over 250 cities around the world and was established to stimulate and inspire cities and communities to become increasingly age-friendly. These primary objectives have evolved over time, and today the aim is to create a model of a city based on the principles of "universal design", that is, to make public and private spaces of the city accessible to every category of people, regardless of age, cultural, social, physical and cognitive conditions.

The accessibility envisaged by the Global Network is multidimensional, but much of it rests on the travel opportunities elderly persons can take advantage of within the urban system, according to its physical and functional characteristics (Gargiulo et al., 2018). In this regard, the scientific community continues to explore issues of improving the elderly population's access to urban services, intervening, on the one hand, on the offer of transport networks to reach a single service of interest (McGrail \& Humphreys, 2014; Lin et al., 2014; Tao \& Cheng, 2019), and, on the other hand, on the physical and functional characteristics of the built environment that influence the "walkability" of the elderly at a neighbourhood scale (Furukawa \& Wang, 2019; Kim et al., 2019; Lee \& Park, 2014). Few studies have been involved in integrating the two approaches by systemising the pedestrian characteristics that influence the elderly population's access to the urban services of their interest.

To address this gap, this study seeks to integrate and overcome limitations of approaches based on accessibility to places and activities by taking into account both the characteristics of the network and the "needs" linked to the behaviour of specific segments of the population. Urban accessibility can be understood as the possibility of a person with any ability to reach and use places and activities of interest without barriers (Gaglione et al., 2019).

To this end, the goal of this research work is to develop a decision support tool to identify interventions that improve pedestrian accessibility (Cottrill et al., 2019). In this work, urban areas are classified by accessibility levels, with levels defined on the basis of the characteristics of the pedestrian network, the offer of urban services, and the behaviour of the three age groups under consideration $(65-69,70-74,>75)$, based on walking speed.

The article is divided as follows: the first section proposes a review of the scientific literature on the topic of accessibility for the elderly population; the second section proposes a methodology to classify urban areas in terms of pedestrian accessibility to urban services to explore usual behaviours of the elderly. In the third section, we demonstrate the application of this methodology in a GIS environment by way of applications to the Fifth Municipality (Vomero and Arenella) of the city of Naples and to the city of Aberdeen. Finally, the fourth section describes the results obtained by comparing the two cities examined.

\footnotetext{
${ }^{1}$ https://www.who.int/ageing/projects/age_friendly_cities_network/en/
} 


\section{STATE OF THE ART}

The organisation of the built environment, and the habits and lifestyles of the users who live in cities have been discussed by many authors (Borst et al., 2008; Marquet et al., 2017; Papa et al., 2018; Riley et al., 2013). Only in recent years, however, has attention been focused on the "weak" segment of the population (children, the elderly, people with disabilities) in relation to the issue of accessibility in urban areas (Gargiulo et al.2019).

The complex relationship between the habits of the elderly and the physical and functional organisation of the urban system has stimulated scientific debate on how to improve accessibility to urban places and services. This is particularly important in soft mobility networks since they constitute the most widespread mobility modes among the elderly and are also the most sustainable for cities (Battara et al., 2018).

In existing research, the scientific community has predominantly addressed the issue of accessibility to urban areas for the elderly population through two different approaches. The first approach looks to optimise transport networks to allow the elderly to reach urban places and services. The second approach identifies characteristics of the built environment that may influence their transport mode choices, with emphasis on pedestrian mobility (Bricocoli et al., 2018). Such approaches have particular implications for the treatment of scales. From a general vantage point, one approach aims at improving access to urban places and services through large transport networks on a territorial scale. A second approach, however, defines the characteristics of the built environment that influence the walkability of the elderly on a neighbourhood scale.

\subsection{URBAN SCALE}

Studies conducted within the first line of research on the elderly segment of the population at urban scales provide essential contributions to the field of spatial accessibility through the use of gravity-based models and contour measures in relation to a single service of interest to the elderly, especially health services, by using a private mode of transport or combining multiple modes of transport (Guagliardo, 2004; Luo \& Wang, 2003; Yang et al., 2006; Wang 2012). These studies often develop a new accessibility indicator aimed at measuring specific features, such as the distance and travel time to reach activities of interest. The results show, through the application of GIS tools, the accessibility levels of single categories of urban services defined in terms of time and distances. Findings from these studies may be used to define the critical areas where actions to improve access to the service should be a priority.

The ability to reach places and services by using local public transport systems and pedestrian networks contributes to reducing the elderly populations' social exclusion (Currie et al., 2010; Langford et al., 2012; Lucas et al., 2016). In this regard, within the same research line, the efficiency of transport networks is examined and defined through network accessibility measures that consider topological characteristics, such as connectivity, in relation to modeled space-time travel requirements of the elderly. More specifically, the travel patterns of the elderly are identified using sample surveys that investigate the lifestyles of older adults (including preferences, constraints and current behaviours). This research considers attributes such as travel distance, travel frequency, and travel start time on weekdays and weekends in relation to the spatial characteristics of public transport networks for travelling to urban services (Ahmad, 2019; Shao et al., 2019; Szeto et., 2017). Understanding these mobility patterns may be useful to optimise travel times and to establish effective and appropriate public transport policy measures in order to improve the mobility of the elderly.

A corpus of scientific literature has also been produced on the preferences of the elderly towards using a specific means of transport, mostly the bus. In particular, this research segment draws on data on spatial characteristics of the public transport network and accessibility to transport systems (closest bus stop, walking distance to tram and railway stations), socio-demographic attributes, and the quality of public transport offered (seat availability, travel stability, waiting time for the service) inferred from sampling surveys. The significance of each of the variables is generally examined using linear or multivariate regression models. The results obtained from the different models aim to develop a more complete understanding of the different lifestyles, attitudes, travel behaviours and needs of the elderly, and their level 
of satisfaction with various public transport modes (Broome et al., 2012; Haustein, 2012; Kotval 2017; Wong et al., 2017).

\subsection{NEIGHBOURHOOD SCALE}

Recent research on the issue have focused on elderly pedestrians' accessibility to urban areas at a neighbourhood scale by examining how to reorganise open and unopened spaces to encourage "active ageing". In particular, these studies have highlighted the physical and natural characteristics of the built environment that influence the "walkability" of the elderly at a neighbourhood scale (Colclough, 2009; Kim et al., 2014; Lee \& Park, 2014). If walking is the "easiest" way of getting around the city, the study of the relationships between the pedestrian behaviour of the elderly and the local urban environment is highly complex.

The scientific debate concerning the study of walkability of the elderly at a neighbourhood scale investigates physical characteristics (related to the geometry and characteristics of the road network, such as sidewalk width and street crossings), environmental considerations (related to elements of urban furniture, such as lighting and benches), and functional characteristics (related to the location of urban services) in determining the safety and attractiveness of a pedestrian path during the walking experience, with the aim of gaining insights into urban design strategies that can improve pedestrian satisfaction (Chen et al., 2019; Gharaveis, 2020).

Many studies have been developed on a micro scale, looking at portions of neighbourhoods, due to a lower tendency of the elderly to walk (for health or physical reasons) and the complexity of the built environment (e.g.pedestrian crossings, traffic lights, presence of ramps, sidewalk paving conditions, vehicle traffic volumes, etc.). These studies have often aimed to deduce perceptions of built environment characteristics and their impact on the choice of the elderly to reach urban services by using a pedestrian path, with consideration of the temporal availability of walking deduced from the use of questionnaires. Multivariate statistical techniques, such as multicriteria analysis and regression models, are used to identify the significance of each of the variables in order to improve pedestrian accessibility in terms of practicability, safety and attractiveness of the pedestrian paths. The collection and localisation of the characteristics is carried out using GIS tools (Bivina \& Parida, 2019; Joo \& Kim, 2011; Li et al., 2015). Furthermore, studies in the GIS environment have developed qualitative or quantitative walkability indicators (Loo \& Lam 2012; Loh et al., 2019; Manaugh \& El-Geneidy, 2011), which, combined with the location of urban services, aim to define the walkability levels of the area under study for the elderly and provide insight into the prioritisation of interventions.

\subsection{SUMMARY}

From the above, we find that previous research and studies show a gap on the subject of accessibility to urban areas for the elderly population. The studies conducted within the first line of research have contributed to defining the levels of accessibility to specific urban services on a territorial scale. Accessibility levels express general time and distance-based access to urban services, but do not take into account the more fine-grained characteristics of the urban environment. Studies developed on a neighbourhood scale, on the other hand, aim to identify characteristics of the built environment that may affect the elderly population's weighted walking time to reach urban neighbourhood services. However, few studies have dealt with integrating the two different approaches on the topic. In this perspective, we propose a methodology that addresses this gap by defining a new measure of pedestrian accessibility on the pedestrian network built starting from the weight of each feature of the pedestrian network (identified through an Analytic Hierarchy Process (AHP) analysis) and behaviours in terms of walking speed. The measure of pedestrian accessibility on the network relates to the travel time of the elderly according to their ability to travel the network in terms of walking speed, which is added to an average time weighted on the characteristics of the built environment. The pedestrian accessibility measure here defines levels of pedestrian accessibility to urban services through joint consideration of built environment characteristics, the preferences and behaviours of elderly pedestrians in the network, and locations of activities of interest at a neighbourhood scale.

\section{METHODOLOGY}


For this study, a five-step methodology was developed to classify urban areas by levels of pedestrian accessibility to key services and also by the behaviour of the elderly (based on average walking speed).

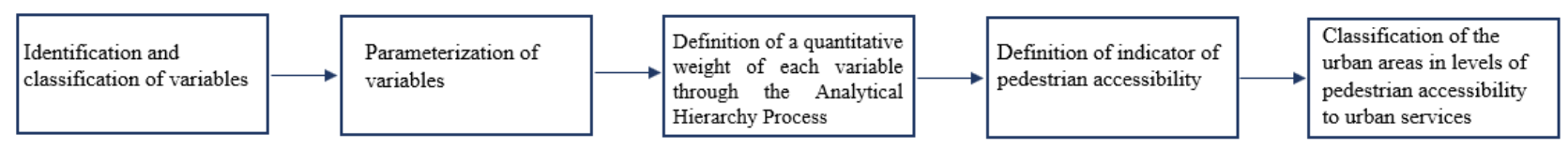

Fig.1 Phases of methodology

The first phase of the study concerned the definition of pedestrian paths suitable for the elderly (Cottrill et al., 2019). The variables were classified according to the following three categories:

- physical characteristics that refer to the geometry and quality of the pedestrian paths, such as the slope and the state of the pavement;

- characteristics of the pedestrian paths and of the surrounding context, such as to perceive support, protection and a sense of safety in walking to places and services, for example the density of lighting and presence of escalators; and

- characteristics of the urban context that refer to the attractiveness of a pedestrian path, for example the presence of green areas or panoramic points.

On the basis of the scientific literature, the most significant variables have been identified following multivariate statistical analysis (Moon et al., 2016; Wey \& Chiu, 2013). In addition, other variables relevant to the research objectives have been introduced with respect to these studies. More specifically, the width of the sidewalks was considered under physical characteristics; in characteristics linked to the sense of safety, the lighting density has been included; and in characteristics of the urban context, the presence of panoramic points and non-main roads has been identified. The choice to exclude main roads is linked to the fact that high vehicle travel speeds on these roads and resulting noise pollution make pedestrian movements of the elderly unsafe and unpleasant. Tab. 1 shows the set of variables proposed. Among all the variables, the density of public lighting is the only one linked to the context, defined as the number of light poles compared to the length of the arcs of the pedestrian network.

Tab.1 Characteristics of the pedestrian network

\begin{tabular}{|c|c|c|c|}
\hline ID & Variable & Measure & Source \\
\hline \multicolumn{4}{|c|}{ Physical characteristics } \\
\hline 1 & $\begin{array}{l}\text { Slope of the links of the } \\
\text { road network }\end{array}$ & $>5 \%=0 \quad<5 \%=1$ & GIS \\
\hline 2 & Sidewalk width & $<1,5 \mathrm{~m}=0 \quad>1,5 \mathrm{~m}=1$ & Google Maps \\
\hline 3 & State of pavement of the sidewalk & $0=$ poor $\quad$ good $=1$ & Google Maps \\
\hline \multicolumn{4}{|c|}{ Characteristics related to the sense of safety } \\
\hline $4 \mathbf{a}$ & Lighting density & $<0,056=0 \quad>0,056=1$ & GIS \\
\hline $4 b$ & Vehicle traffic volume & $>17,5 \mathrm{~m}=0 \quad<9 \mathrm{~m}=1$ & GIS \\
\hline 5 & Presence of escalators & $\mathrm{No}=0 \quad \mathrm{Yes}=1$ & Google Maps \\
\hline 6 & Presence of bench & $\mathrm{No}=0 \quad \mathrm{Yes}=1$ & Google Maps \\
\hline \multicolumn{4}{|c|}{ Urban context characteristics } \\
\hline 7 & Presence of green areas & $\mathrm{No}=0 \quad \mathrm{Yes}=1$ & Google Maps \\
\hline 8 & Presence of panoramic points & $\mathrm{No}=0 \quad \mathrm{Yes}=1$ & Google Maps \\
\hline 9 & Non-main roads & $\mathrm{No}=0 \quad \mathrm{Yes}=1$ & Google Maps \\
\hline
\end{tabular}

The second phase of the study concerned the parameterisation of each variable of the proposed set. In particular, some variables related to the physical characteristics of a pedestrian path, such as the slope and 
width of the pavement, are measured on a quantitative scale. To convert these characteristics to a dichotomous scale, conditions favourable to an elderly person along the route have been defined (for example, slope $<5 \%$, pavement width $>1.5 \mathrm{~m}$, as well as the "difficult" factors that an elderly person may encounter along the route). To define the latter, we consulted documents such as the Highway Code (Legislative Decree of April 30, 1992, no. 285), which regulates the circulation of vehicles and pedestrians on the road. These showed that slopes $>5 \%$ and pavement widths $<1.5 \mathrm{~m}$ present an architectural barrier for users who walk in the city, in particular for vulnerable groups of the population. For the characteristics related to the sense of safety, lighting density and volumes of vehicular traffic were considered. For lighting density, the favourable/unfavourable criteria for the elderly along a pedestrian path were defined based on the number of light poles along the length of the arc in the GIS environment using the natural breaks method. For the volume of vehicular traffic, the criteria have been established on the basis of the type of road and its width, as governed by the Ministry of Infrastructure and Transport (MIT) 11/05/2001 (Publication of the regulation on the G.U. n. 3 of 04/01/2002, Functional and geometric standards for the construction of roads).

Other variables are measured on a qualitative scale (presence/absence). It is worth noting that the pavement condition has been defined by means of a direct survey on the territory where the arcs of the network present, for example, a rough pavement, cracks, or discontinuity of the material. The set of variables has been associated in the GIS environment with each arc of the pedestrian graph.

To take a quantitative weight of each of the variables considered and to understand the relationships between each of the variables examined, in phase three a multicriteria analysis activity was undertaken, using the Analytic Hierarchy Process (AHP). The AHP method (Saaty, 1980) has been used to define the weights for each of the variables considered. Within the scientific reference framework, it has been widely used to improve areas of the city in terms of pedestrian accessibility by identifying, on the one hand, the factors that can influence the pedestrian nature of a general user (Oswald \& Phillips, 2015; Sayyadi \& Awasthi, 2013) and, on the other, through an analysis of the built environment (also in relation to the presence of health and recreational facilities near the areas examined) combined with the use of other mobility modes, such as car sharing and local public transport (Cerin et al. 2012; Kim et al. 2011). The AHP method, developed by the mathematician Thomas L. Saaty (1980), is based on pairwise comparisons of options to derive the weight of one variable compared to the others. It is capable to convert qualitative data into numerical values, which is useful for classifying each alternative on a numerical basis, constituting the statistical technique akin to the set of variables proposed.

The AHP phases are defined as follows:

- Establish the pairwise comparison matrix, defined in linear algebra as the eigenvector matrix. This matrix has the characteristic of being a square matrix $(n * n)$, symmetrical and diagonal.

- Define the AHP pairwise comparison by assigning judgements on a scale defined by decision makers (or experts). In order to assign the influence of each variable, the Delphi method was adopted. This method involves obtaining input from a panel of experts, such as academics, researchers and technicians from the area, who have different skills and knowledge on the topic. Each member of the panel was asked to respond to a questionnaire identifying the influence of a set of identified characteristics on the choice of a pedestrian path for the elderly. Their reported judgements were then transposed on a scale of values of 1 to 9 (Saaty, 1980) as in Tab.2.

Tab.2 Conversion of Verbal Values to Numerical Values in the AHP method (Saaty, 1980)

\begin{tabular}{ll}
\hline Value & Interpretation \\
\hline $\mathbf{1}$ & Measure $i$ and Measure $j$ have equal influence \\
$\mathbf{3}$ & Measure $i$ has slightly more influence than Measure $j$ \\
$\mathbf{5}$ & Measure $i$ has more influence than Measure $j$ \\
$\mathbf{7}$ & Measure $i$ has strongly more influence than Measure $j$ \\
$\mathbf{9}$ & Measure $i$ has absolutely more influence than Measure $j$ \\
$\mathbf{2 , 4 , 6 , 8}$ & Intermediate values can be applied between the above judgements \\
$\mathbf{1 / 3}$ & Measure $i$ has slightly less influence than Measure $j$ \\
$\mathbf{1} / \mathbf{5}$ & Measure $i$ has less influence than Measure $j$ \\
$\mathbf{1 / 7}$ & Measure $i$ has strongly less influence than Measure $j$ \\
\hline
\end{tabular}




\begin{tabular}{ll}
\hline $\mathbf{1} / \mathbf{9}$ & Measure $i$ has absolutely less influence than Measure $j$ \\
$\mathbf{1} 2,1 / 4$, etc. & Intermediate values can be applied between the above judgements \\
\hline
\end{tabular}

For each row $i$ with respect to column $j$ of the matrix, a score is attributed on a previously illustrated scale; conversely, the score of the decision of row $j$ with respect to column $i$ will be equal to its reciprocal. The result of the comparison is the dominance coefficient aij, which represents the estimate of the dominance of the element $i$ over the element $j$. Following the initial score determination, we next:

- Normalize the values of the matrix (defined as the eigenvector matrix) so as to calculate the weight of each variable as the average of each row $i$ of the matrix. These weights define the priorities of the individual variables.

- Calculate the weighted average of each variable (on the weights defined in the previous point), which is useful for estimating the weight of each variable on the judgement attributed by multiplying each column $j$ of the matrix of the comparison in pairs by the weight relative to that column.

- Verify the consistency or inconsistency of the assessments assigned by calculating the consistency index and the consistency ratio of the matrix. The consistency of the matrix is useful for checking whether the judgements provided by the experts within the comparison matrix are consistent with the assessments made.

The consistency index is expressed by the following formula

$$
\mathrm{CI}=\left(\kappa_{\max }-\mathrm{n}\right) /(\mathrm{n}-1)
$$

where $K_{\max }$ constitutes the maximum eigenvalue of the matrix, in turn calculated as the ratio between the weighted average of each variable and the weight of each variable and $n$ is the dimension of the matrix. This index constitutes the indispensable premise for calculating the coherence ratio of the matrix expressed as:

$$
\text { Consistency ratio }(\mathrm{CR})=\mathrm{CI} / \mathrm{RI}
$$

where RI is equal to the random consistency index defined by Saaty (1980) based on the size of the matrix (Tab.3).

Tab.3 Values of RI in the AHP Method

\begin{tabular}{lllllllllll}
\hline$R I$ & 0 & 0 & 0.58 & 0.9 & 1.12 & 1.24 & 1.32 & 1.41 & 1.45 & 1.49 \\
\hline$n$ & 1 & 2 & 3 & 4 & 5 & 6 & 7 & 8 & 9 & 10 \\
\hline
\end{tabular}

To consider the coherent judgements within the pairwise comparison matrix, $\mathrm{CR}<0.1(10 \%)$ is placed as a constraint (Saaty, 2012). If this CR exceeds one conventionally set equal to $10 \%$ of the R.I. value, it is necessary to review the judgements in the pairwise comparison matrix to identify the cause of the inconsistency and correct it.

The weights deducted from the AHP have been associated with the arcs of the pedestrian network in the GIS environment. Each weight was associated with both the "difficult" factors that the elderly person encounters along the route to access services (such as pavement in poor condition or high volume of vehicular traffic), and those that constitute architectural barriers for elderly (such as slope $>5 \%$ or width of the sidewalk $<1.5 \mathrm{~m}$ ), while simultaneously recognising the arcs of the network as a favourable factor.

The definition of weights with AHP was the starting point in phase four for the development of the accessibility measure. More specifically, the measurement of pedestrian accessibility on the network relates the controls of the elderly in terms of ability to walk every single arc of the network to the weight of the individual characteristics of the pedestrian network, defined in the previous phase.

More specifically, the accessibility index outlined on the pedestrian network graph is as follows:

$$
\text { Accessibility Pedestrian Network }=T_{i j}+\sum_{i j}^{n=1}\left(M_{i j} \times T_{i j}\right)
$$


where:

$T_{i j}$ is the average walking time of the elderly person from node $i$ to node $j$ of the pedestrian graph

$\sum_{i j}^{n=1}\left(M_{i j}\right)$ is the sum of the weights of each characteristic of the pedestrian network from node $i$ to node $j$

$\sum_{i j}^{n=1}\left(M_{i j} x T_{i j}\right)$ is the average time weighted on the weights of the variables from node $i$ to node $j$.

The new accessibility measure defined on the pedestrian network graph is given by two parameters. The first parameter is the average walking time for the elderly, calculated as the ratio between the lengths of the individual arcs of the pedestrian network and the walking speed. In turn, the walking speed of the elderly person was inferred from the study of the scientific literature, in particular of the research carried out by Weber (2016) which determined these values based on the main socio-economic characteristics of the elderly population.

The values identified are the following:

- for the population group aged $65-69$, the average walking speed is $0.81 \mathrm{~m} / \mathrm{s}$.

- for the population aged 70-74, the average walking speed is $0.69 \mathrm{~m} / \mathrm{s}$.

- for the population aged over 75 , the average walking speed is $0.60 \mathrm{~m} / \mathrm{s}$.

The second parameter is the weighted average time determined as the product of the average walking time by the elderly person for the weights of the individual characteristics of the pedestrian network inferred from the AHP in phase three of the methodology and associated with the pedestrian network.

The pedestrian accessibility index defines an average time on each pedestrian route based on the effective ability of the elderly person to walk on each arc of the network. At the same time, an average time is weighted based on the characteristics of each pedestrian path. The weighted average time increases if the pedestrian paths have more "difficult" factors, for example inadequate pavement conditions or high slopes compared to favourable conditions; therefore, the elderly person uses a higher "cost" in terms of time in the arcs of the network that are not suitable for their needs. The logic is to create a synthetic indicator from the behaviour of the elderly on each arc of the pedestrian network with the physical characteristics, safety and urban context, in order to define accessibility on the pedestrian graph in relation to the possibility of a person with any ability to reach and use places and activities of interest.

In phase five of the methodology, we use the defined times on each arc of the pedestrian network and the distribution and location of key types of service for the elderly segment of the population to classify urban areas in terms of pedestrian accessibility to urban services, using a network analysis tool in the GIS environment. Pedestrian access levels are defined through isochrones, which delineate the areas covered by urban services that are reachable within a given time interval by the different age categories identified. More specifically, urban areas have been classified into three specific time intervals (5, 10, and 15 minutes) (Lovett et al., 2002; Weber \& Kwan 2002) by each urban service. The classification of urban areas in terms of pedestrian accessibility to urban services is an indispensable premise for the construction of a tool to support the public decision maker in undertaking interventions (linear, punctual and areal) on portions of municipal territory, in order to improve the quality of life of the elderly population.

\section{RESULTS OF THE PEDESTRIAN PATHS}

The described methodology has been tested in two different urban areas: Naples, Italy and Aberdeen, Scotland. In particular, the area selected in Naples includes the two districts of Vomero and Arenella, while the Aberdeen area includes multiple districts. More specifically, more districts of Aberdeen have been chosen than the two districts of Naples to compare two districts of approximately equal population. In addition, the choice of the districts is motivated by the profound morphological, settlement and functional differences that characterise them.

In more detail, the Vomero district is characterised by a compact and planned fabric, made on a unitary design. In practice, this neighbourhood is designed with a checkerboard pattern, much like the areas of 
Piazza Vanvitelli and Medaglie d'Oro. The Arenella district, on the other hand, is of a more recent formation than the Vomero district, and includes areas such as those related to the Rione Alto district, adjacent to the hospital area, the Policlinico and via Domenico Fontana (Fig.2). These areas are characterised by an unplanned fabric, in which the building process began as a consequence of the building saturation of the nearby Vomero district. The hilly orographic conformation of the Neapolitan area (from 150 to $375 \mathrm{~m}$ above sea level) influences the choice of spaces and services for the elderly, thus representing an important element in defining strategies and policies aimed at improving accessibility to urban services for the elderly population.

For Aberdeen, both the neighbourhood of Old Aberdeen and newer areas within Aberdeen (which comprises a number of neighbourhoods, as seen in Fig. 3) were investigated. Old Aberdeen is the historical part of the city, characterised by dense and compact development in which road links were created to facilitate movement both within Old Aberdeen and into neighbouring areas. Newer parts of Aberdeen have been subject to redevelopment since the 1970s. In Aberdeen, the proximity to the port has given rise to redevelopment processes favouring the presence of greater urban services (Fig.3).

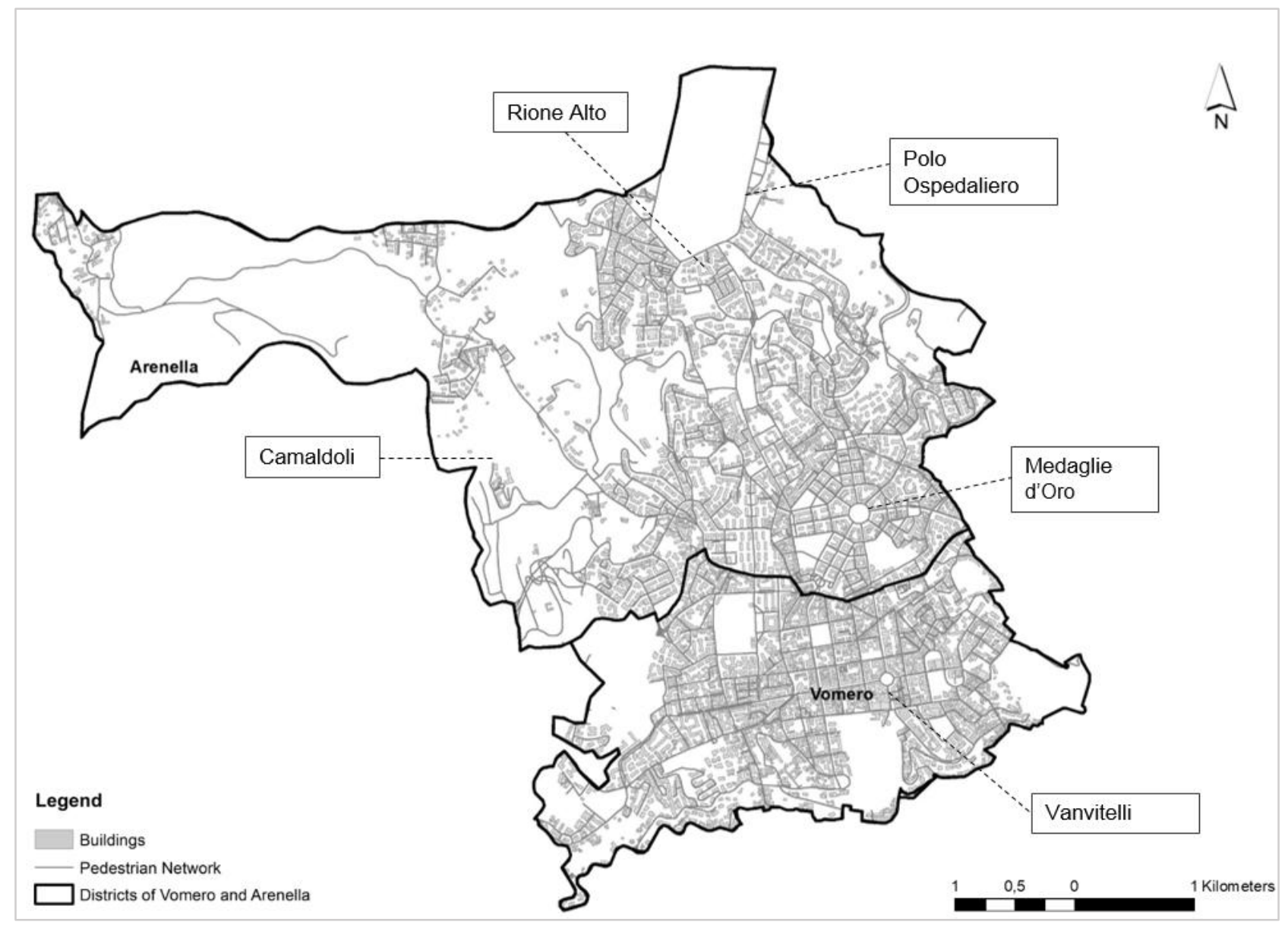

Fig.2 Vomero and Arenella districts in the city of Naples. 


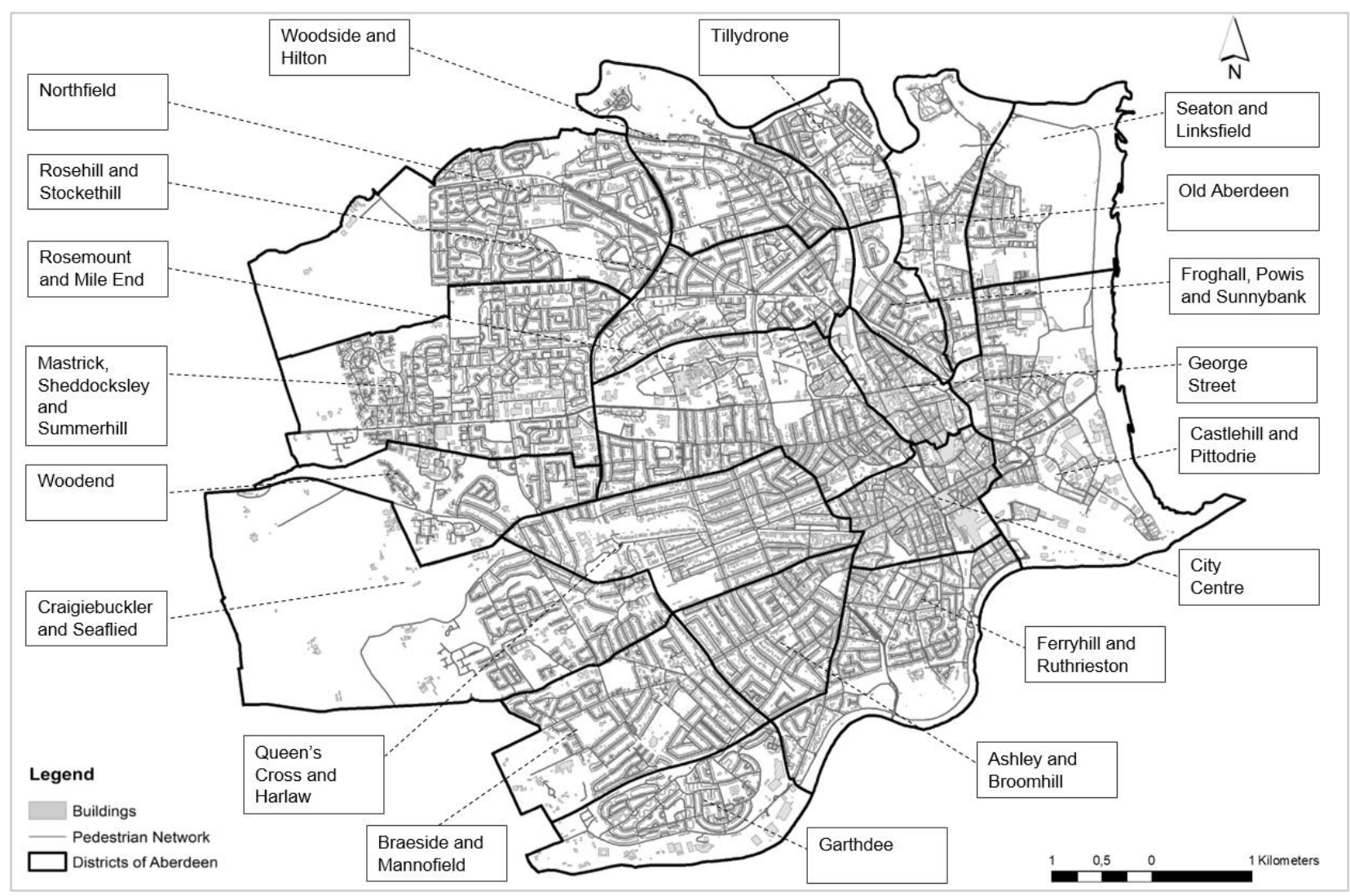

Fig.3 Districts of the city of Aberdeen

The application mainly concerned the definition of pedestrian paths suitable for the elderly. The set of variables outlined has been associated, in the GIS environment, with each arc of the pedestrian graph of the Vomero and Arenella districts and of the districts of Aberdeen. It should be specified that it was possible to detect the lighting density only for the Neapolitan context and that for the city of Aberdeen the volume of vehicular traffic was considered between the variables. The weight of each variable associated with the pedestrian network (physical characteristics, linked to the sense of safety and protection of the elderly, and the urban context) was defined using computer software (Super Decision Version $3.2^{2}$ ) aimed at executing AHP. The results obtained for the districts of Naples and Aberdeen relating to the overall weights of the characteristics of the pedestrian network are shown below. Tables 4 to 13 outline the outputs for the two territorial contexts of Naples (Tables 4-8) and Aberdeen (Tables 9-13), as described below:

- Tables 4-9 show the outputs obtained for the two territorial contexts of the pairwise comparison between the variables. Such tables have the characteristic of being symmetrical and diagonal. With respect to the main diagonal on the right of the table, in each row $i$ with respect to column $j$ of the matrix the scores on a scale from 1 to 9 are reported by the AHP experts. On the left, vice versa, the decision values of row $j$ with respect to column $i$ equal to their reciprocal have been inferred.

- Tables 5-10 highlight the normalisation process of the matrix so that the sum of the elements is equal to 1 and defines in the last column of the tables the option weight vector, or the priorities relating to the individual variables. The outputs obtained from the option weight vector were inferred as the average of each row of the normalised pairwise comparison tables.

- Tables 6-11 show the influence of the judgement attributed by the decision maker for the weight vector option, which was defined for each judgement element by multiplying each column $j$ of the pairwise comparison table (table 4-5) for the weight relative to that column, with the aim of defining a weighted sum value.

\footnotetext{
${ }^{2}$ http://www.superdecisions.com/
} 
- Tables 7-12 demonstrate the relationship between the defined weighted sum value and option weight vector for each variable. The average value of this ratio defines the maximum eigenvalue of the matrix, which is useful for defining its maturity index in order to verify the consistency of the judgements attributed in relation to the number of variables, finally to define the consistency ratio of the matrix itself.

- Tables 8-13 summarise the weights inferred for each single variable examined and the relative weight in percentage terms.

Table 4 Pairwise Comparison of set of variables on the city of Naples

\begin{tabular}{|c|c|c|c|c|c|c|c|c|c|c|}
\hline Row $i$ & Column $j$ & 1 & 2 & 3 & $4^{\circ}$ & 5 & 6 & 7 & 8 & 9 \\
\hline 1 & & 1.00 & 3.00 & 4.00 & 4.00 & 1.00 & 5.00 & 6.00 & 7.00 & 4.00 \\
\hline 2 & & 0.33 & 1.00 & 3.00 & 4.00 & 1.00 & 4.00 & 5.00 & 6.00 & 3.00 \\
\hline 3 & & 0.25 & 0.33 & 1.00 & 3.00 & 0.25 & 3.00 & 4.00 & 5.00 & 3.00 \\
\hline $4^{\circ}$ & & 0.33 & 0.25 & 0.33 & 1.00 & 0.20 & 4.00 & 3.00 & 5.00 & 0.33 \\
\hline 5 & & 1.00 & 1.00 & 4.00 & 5.00 & 1.00 & 4.00 & 4.00 & 5.00 & 3.00 \\
\hline 6 & & 0.20 & 0.25 & 0.33 & 0.25 & 0.25 & 1.00 & 3.00 & 4.00 & 0.33 \\
\hline 7 & & 0.17 & 0.20 & 0.25 & 0.33 & 0.25 & 0.33 & 1.00 & 4.00 & 0.20 \\
\hline 8 & & 0.14 & 0.17 & 0.20 & 0.20 & 0.20 & 0.25 & 0.25 & 1.00 & 0.20 \\
\hline \multirow[t]{2}{*}{9} & & 0.25 & 0.33 & 0.33 & 3.03 & 0.33 & 3.03 & 5.00 & 5.00 & 1.00 \\
\hline & & 3.68 & 6.53 & 13.45 & 20.81 & 4.48 & 24.61 & 31.25 & 42.00 & 15.06 \\
\hline
\end{tabular}

Table 5 Normalised set of variables and weights on the city of Naples

\begin{tabular}{llllllllllll}
\hline Row $\boldsymbol{i}$ & Column $\boldsymbol{j}$ & $\mathbf{1}$ & $\mathbf{2}$ & $\mathbf{3}$ & $\mathbf{4 a}$ & $\mathbf{5}$ & $\mathbf{6}$ & $\mathbf{7}$ & $\mathbf{8}$ & $\mathbf{9}$ & $\begin{array}{c}\text { Option } \\
\text { Weight } \\
\text { Vector }\end{array}$ \\
\hline $\mathbf{1}$ & 0.27 & 0.46 & 0.30 & 0.19 & 0.22 & 0.20 & 0.19 & 0.17 & 0.27 & 0.25 \\
$\mathbf{2}$ & 0.09 & 0.15 & 0.22 & 0.19 & 0.22 & 0,16 & 0.16 & 0.14 & 0.20 & 0.17 \\
$\mathbf{3}$ & 0.07 & 0.05 & 0.07 & 0.14 & 0.06 & 0.12 & 0.13 & 0.12 & 0.20 & 0.11 \\
$\mathbf{4}^{\circ}$ & 0.09 & 0.04 & 0.02 & 0.05 & 0.04 & 0.16 & 0.10 & 0.12 & 0.02 & 0.07 \\
$\mathbf{5}$ & 0.27 & 0.15 & 0.30 & 0.24 & 0.22 & 0.16 & 0.13 & 0.12 & 0.20 & 0.20 \\
$\mathbf{6}$ & 0.05 & 0.04 & 0.02 & 0.01 & 0.06 & 0.04 & 0.10 & 0.10 & 0.02 & 0.05 \\
$\mathbf{7}$ & 0.05 & 0.03 & 0.02 & 0.02 & 0.06 & 0.01 & 0.03 & 0.10 & 0.01 & 0.04 \\
$\mathbf{8}$ & 0.04 & 0.03 & 0.01 & 0.01 & 0.04 & 0.01 & 0.01 & 0.02 & 0.013 & 0.02 \\
$\mathbf{9}$ & 0.07 & 0.05 & 0.02 & 0.15 & 0.07 & 0.12 & 0.16 & 0.12 & 0.07 & 0.09 \\
\hline & 1.00 & 1.00 & 1.00 & 1.00 & 1.00 & 1.00 & 1.00 & 1.00 & 1.00 & \\
\hline
\end{tabular}

Table 6 Weighted average of the variables on the city of Naples

\begin{tabular}{llllllllllll}
\hline Row $\boldsymbol{i}$ & Column $\boldsymbol{j}$ & $\mathbf{1}$ & $\mathbf{2}$ & $\mathbf{3}$ & $\mathbf{4 a}$ & $\mathbf{5}$ & $\mathbf{6}$ & $\mathbf{7}$ & $\mathbf{8}$ & $\mathbf{9}$ & $\begin{array}{l}\text { Weighted } \\
\text { Sum } \\
\text { Value }\end{array}$ \\
\hline $\mathbf{1}$ & & & & & & & & & & \\
$\mathbf{2}$ & 0.25 & 0.52 & 0.43 & 0.29 & 0.20 & 0.24 & 0.21 & 0.15 & 0.37 & 2.66 \\
$\mathbf{3}$ & 0.08 & 0.17 & 0.32 & 0.29 & 0.20 & 0.20 & 0.18 & 0.13 & 0.28 & 2.00 \\
$\mathbf{4}^{\circ}$ & 0.06 & 0.06 & 0.11 & 0.22 & 0.05 & 0.15 & 0.14 & 0.10 & 0.28 & 1.20 \\
$\mathbf{5}$ & 0.08 & 0.04 & 0.04 & 0.07 & 0.04 & 0.20 & 0.11 & 0.10 & 0.03 & 0.71 \\
$\mathbf{6}$ & 0.25 & 0.17 & 0.43 & 0.36 & 0.20 & 0.20 & 0.14 & 0.10 & 0.28 & 2.10 \\
$\mathbf{7}$ & 0.05 & 0.04 & 0.04 & 0.02 & 0.05 & 0.05 & 0.11 & 0.08 & 0.03 & 0.50 \\
$\mathbf{8}$ & 0.04 & 0.03 & 0.03 & 0.02 & 0.05 & 0.02 & 0.04 & 0.08 & 0.02 & 0.30 \\
$\mathbf{9}$ & 0.04 & 0.03 & 0.02 & 0.01 & 0.04 & 0.01 & 0.036 & 0.02 & 0.02 & 0.23 \\
\hline
\end{tabular}


Table 7 Definition of weighted sum value/option weight vector for variables on the city of Naples

\begin{tabular}{llll}
\hline Variables & Weighted Sum Value & Option Weight Vector & $\begin{array}{l}\text { Weighted Sum Value/Option } \\
\text { Weight Vector }\end{array}$ \\
\hline $\mathbf{1}$ & 2.66 & 0.25 & 11.00 \\
$\mathbf{2}$ & 1.84 & 0.17 & 11.00 \\
$\mathbf{3}$ & 1.16 & 0.11 & 11.00 \\
$\mathbf{4}^{\circ}$ & 0.71 & 0.07 & 10.00 \\
$\mathbf{5}$ & 2.13 & 0.20 & 11.00 \\
$\mathbf{6}$ & 0.47 & 0.05 & 10.00 \\
$\mathbf{7}$ & 0.33 & 0.04 & 9.00 \\
$\mathbf{8}$ & 0.23 & 0.02 & 11.00 \\
$\mathbf{9}$ & 0.79 & 0.09 & 9.00 \\
\hline
\end{tabular}

Note: $\lambda \max =$ Average $($ Weighted Sum Value/Option Weight $)=10$; Consistency Index $($ C.I. $)=(\lambda \max -\mathrm{n}) /(\mathrm{n}-1)$; where $\mathrm{n}=\mathrm{number}$ of compared options (measures) $=9$; Consistency Index (C.I.) $=0,139$; Consistency Ratio = C.I. $/$ Random Index $($ R.I. $)=0,096<0.1$ matrix consistency OK

Table 8 Weights of variables on the city of Naples

\begin{tabular}{lll}
\hline Variables & Option Weight Vector & $\begin{array}{l}\text { Option Weight } \\
\text { Vector (\%) }\end{array}$ \\
\hline $\mathbf{1}$ & 0.25 & $25 \%$ \\
$\mathbf{2}$ & 0.17 & $17 \%$ \\
$\mathbf{3}$ & 0.11 & $11 \%$ \\
$\mathbf{4}^{\circ}$ & 0.07 & $7 \%$ \\
$\mathbf{5}$ & 0.20 & $20 \%$ \\
$\mathbf{6}$ & 0.05 & $5 \%$ \\
$\mathbf{7}$ & 0.04 & $4 \%$ \\
$\mathbf{8}$ & 0.02 & $2 \%$ \\
$\mathbf{9}$ & 0.09 & $9 \%$ \\
\hline
\end{tabular}

Table 9 Pairwise Comparison of set of variables on the city of Aberdeen

\begin{tabular}{|c|c|c|c|c|c|c|c|c|c|c|}
\hline Row $i$ & Column $j$ & 1 & 2 & 3 & $4 b$ & 5 & 6 & 7 & 8 & 9 \\
\hline 1 & & 1.00 & 0.25 & 0.25 & 0.25 & 1.00 & 3.00 & 4.00 & 6.00 & 2.00 \\
\hline 2 & & 4.00 & 1.00 & 4.00 & 3.00 & 5.00 & 4.00 & 5.00 & 7.00 & 4.00 \\
\hline 3 & & 4.00 & 0.25 & 1.00 & 3.00 & 4.00 & 4.00 & 5.00 & 7.00 & 3.00 \\
\hline $4 b$ & & 0.25 & 0.33 & 0.33 & 1.00 & 3.00 & 4.00 & 5.00 & 7.00 & 1.00 \\
\hline 5 & & 1.00 & 0.20 & 0.25 & 0.33 & 1.00 & 3.00 & 4.00 & 6.00 & 2.00 \\
\hline 6 & & 0.33 & 0.25 & 0.25 & 0.25 & 0.33 & 1.00 & 4.00 & 5.00 & 0.25 \\
\hline 7 & & 0.25 & 0.20 & 0.20 & 0.20 & 0.25 & 0.25 & 1.00 & 4.00 & 0.20 \\
\hline 8 & & 0.17 & 0.14 & 0.14 & 0.14 & 0.17 & 0.20 & 0.25 & 1.00 & 0.14 \\
\hline \multirow[t]{2}{*}{9} & & 0.50 & 0.25 & 0.33 & 1.00 & 0.50 & 4.00 & 5.00 & 7.14 & 1.00 \\
\hline & & 11.50 & 2.88 & 6.76 & 9.18 & 15.25 & 23.45 & 33.25 & 50.14 & 13.59 \\
\hline
\end{tabular}


Table 10 Normalised set of variables and weights on the city of Aberdeen

\begin{tabular}{|c|c|c|c|c|c|c|c|c|c|c|c|}
\hline Row $i$ & Column $j$ & 1 & 2 & 3 & $4 b$ & 5 & 6 & 7 & 8 & 9 & $\begin{array}{l}\text { Option } \\
\text { Weight } \\
\text { Vector }\end{array}$ \\
\hline 1 & & 0.09 & 0.09 & 0.037 & 0.03 & 0.07 & 0.13 & 0.12 & 0.12 & 0.15 & 0.09 \\
\hline 2 & & 0.35 & 0.35 & 0.592 & 0.33 & 0.33 & 0.17 & 0.15 & 0.14 & 0.29 & 0.30 \\
\hline 3 & & 0.35 & 0.09 & 0.15 & 0.33 & 0.26 & 0.17 & 0.15 & 0.14 & 0.22 & 0.21 \\
\hline $4 b$ & & 0.02 & 0.12 & 0.05 & 0.11 & 0.20 & 0.17 & 0.15 & 0.14 & 0.07 & 0.11 \\
\hline 5 & & 0.09 & 0.07 & 0.04 & 0.04 & 0.07 & 0.13 & 0.12 & 0.12 & 0.15 & 0.09 \\
\hline 6 & & 0.03 & 0.09 & 0.04 & 0.03 & 0.02 & 0.04 & 0.12 & 0.10 & 0.02 & 0.05 \\
\hline 7 & & 0.02 & 0.07 & 0.03 & 0.02 & 0.02 & 0.01 & 0.03 & 0.08 & 0.01 & 0.03 \\
\hline 8 & & 0.01 & 0.05 & 0.02 & 0.02 & 0.01 & 0.01 & 0.01 & 0.02 & 0.010 & 0.02 \\
\hline \multirow[t]{2}{*}{9} & & 0.04 & 0.09 & 0.05 & 0.11 & 0.03 & 0.17 & 0.15 & 0.14 & 0.07 & 0.10 \\
\hline & & 1.00 & 1.00 & 1.00 & 1.00 & 1.00 & 1.00 & 1.00 & 1.00 & 1.00 & \\
\hline
\end{tabular}

Table 11 Weighted average of the variables on the city of Aberdeen

\begin{tabular}{|c|c|c|c|c|c|c|c|c|c|c|c|}
\hline Row $i$ & Column $j$ & 1 & 2 & 3 & $4 b$ & 5 & 6 & 7 & 8 & 9 & $\begin{array}{l}\text { Weighted } \\
\text { Sum } \\
\text { Value }\end{array}$ \\
\hline 1 & & 0.09 & 0.07 & 0.05 & 0.03 & 0.09 & 0.16 & 0.13 & 0.11 & 0.19 & 0.92 \\
\hline 2 & & 0.36 & 0.30 & 0.82 & 0.34 & 0.45 & 0.21 & 0.16 & 0.12 & 0.38 & 3.00 \\
\hline 3 & & 0.36 & 0.07 & 0.21 & 0.34 & 0.36 & 0.21 & 0.16 & 0.12 & 0.29 & 2.10 \\
\hline $4 b$ & & 0.02 & 0.10 & 0.07 & 0.11 & 0.27 & 0.21 & 0.16 & 0.12 & 0.10 & 1.17 \\
\hline 5 & & 0.09 & 0.06 & 0.05 & 0.04 & 0.09 & 0.16 & 0.13 & 0.11 & 0.19 & 0.90 \\
\hline 6 & & 0.03 & 0.07 & 0.05 & 0.03 & 0.03 & 0.05 & 0.13 & 0.09 & 0.02 & 0.50 \\
\hline 7 & & 0.02 & 0.06 & 0.04 & 0.02 & 0.02 & 0.01 & 0.03 & 0.07 & 0.02 & 0.30 \\
\hline 8 & & 0.02 & 0.04 & 0.03 & 0.02 & 0.02 & 0.01 & 0.033 & 0.02 & 0.01 & 0.19 \\
\hline 9 & & 0.05 & 0.07 & 0.07 & 0.11 & 0.05 & 0.21 & 0.008 & 0.13 & 0.10 & 0.79 \\
\hline
\end{tabular}

Table 12 Definition of weighted sum value/option weight vector for variables on the city of Aberdeen

\begin{tabular}{llll}
\hline Variable & Weighted Sum Value & Option Weight Vector & $\begin{array}{l}\text { Weighted Sum Value/Option } \\
\text { Weight Vector }\end{array}$ \\
\hline $\mathbf{1}$ & 0.92 & 0.09 & 10.00 \\
$\mathbf{2}$ & 3.16 & 0.30 & 11.00 \\
$\mathbf{3}$ & 2.13 & 0.21 & 10.00 \\
$\mathbf{4 b}$ & 1.17 & 0.11 & 10.00 \\
$\mathbf{5}$ & 0.92 & 0.09 & 10.00 \\
$\mathbf{6}$ & 0.51 & 0.05 & 10.00 \\
$\mathbf{7}$ & 0.30 & 0.03 & 9.00 \\
$\mathbf{8}$ & 0.19 & 0.02 & 11.00 \\
$\mathbf{9}$ & 0.79 & 0.10 & 8.00
\end{tabular}

Note: $\lambda \max =$ Average $($ Weighted Sum Value/Option Weight $)=10$; Consistency Index (C.I. $)=(\lambda \max -\mathrm{n}) /(\mathrm{n}-1)$; where $\mathrm{n}=\mathrm{number}$ of compared options (measures) $=9$; Consistency Index (C.I. $)=0,12$; Consistency Ratio $=$ C.I. $/$ Random Index $($ R.I. $)=0,0832<0.1$ matrix consistency OK 
Table 13 Weighted average of the variables on the city of Aberdeen

\begin{tabular}{lll}
\hline Variable & $\begin{array}{l}\text { Option Weight } \\
\text { Vector }\end{array}$ & $\begin{array}{l}\text { Option Weight } \\
\text { Vector (\%) }\end{array}$ \\
\hline $\mathbf{1}$ & 0.09 & $9 \%$ \\
$\mathbf{2}$ & 0.30 & $30 \%$ \\
$\mathbf{3}$ & 0.21 & $21 \%$ \\
$\mathbf{4 b}$ & 0.11 & $11 \%$ \\
$\mathbf{5}$ & 0.09 & $9 \%$ \\
$\mathbf{6}$ & 0.05 & $5 \%$ \\
$\mathbf{7}$ & 0.03 & $3 \%$ \\
$\mathbf{8}$ & 0.02 & $2 \%$ \\
$\mathbf{9}$ & 0.10 & $10 \%$ \\
\hline
\end{tabular}

\subsection{RESULTS OF MEASURE OF PEDESTRIAN ACCESSIBILITY}

In accordance with the previous section, the definition of the weights of single variables on each arc of the pedestrian network was the starting point for determining the measure of pedestrian accessibility expressed in terms of time associated with the graph of the pedestrian network of the fifth municipality of Naples and Aberdeen. The travel times defined on the basis of the walking speed of the elderly, together with the weight of the characteristics shown on the pedestrian graph and the distribution and location of services, were the inputs to classify the areas of the municipal territory (through the use of a tool network analysis) in three classes (one for each of the three-time intervals of 5, 10 and 15 minutes). With this in mind, the results obtained show that the areas in which it is possible to reach the different services in established time intervals ( 5 minutes yellow, 10 minutes green and 15 minutes red) change by reason of the characteristics of the pedestrian network. The results include those achieved for one of the most significant segments of the elderly population - the over 75 - and for each type of service for the territorial contexts of Naples and Aberdeen (health fig. 4-5, economic fig. 6-7, cultural fig. 8-9, leisure fig. 10-11 and commercial fig.12-13).

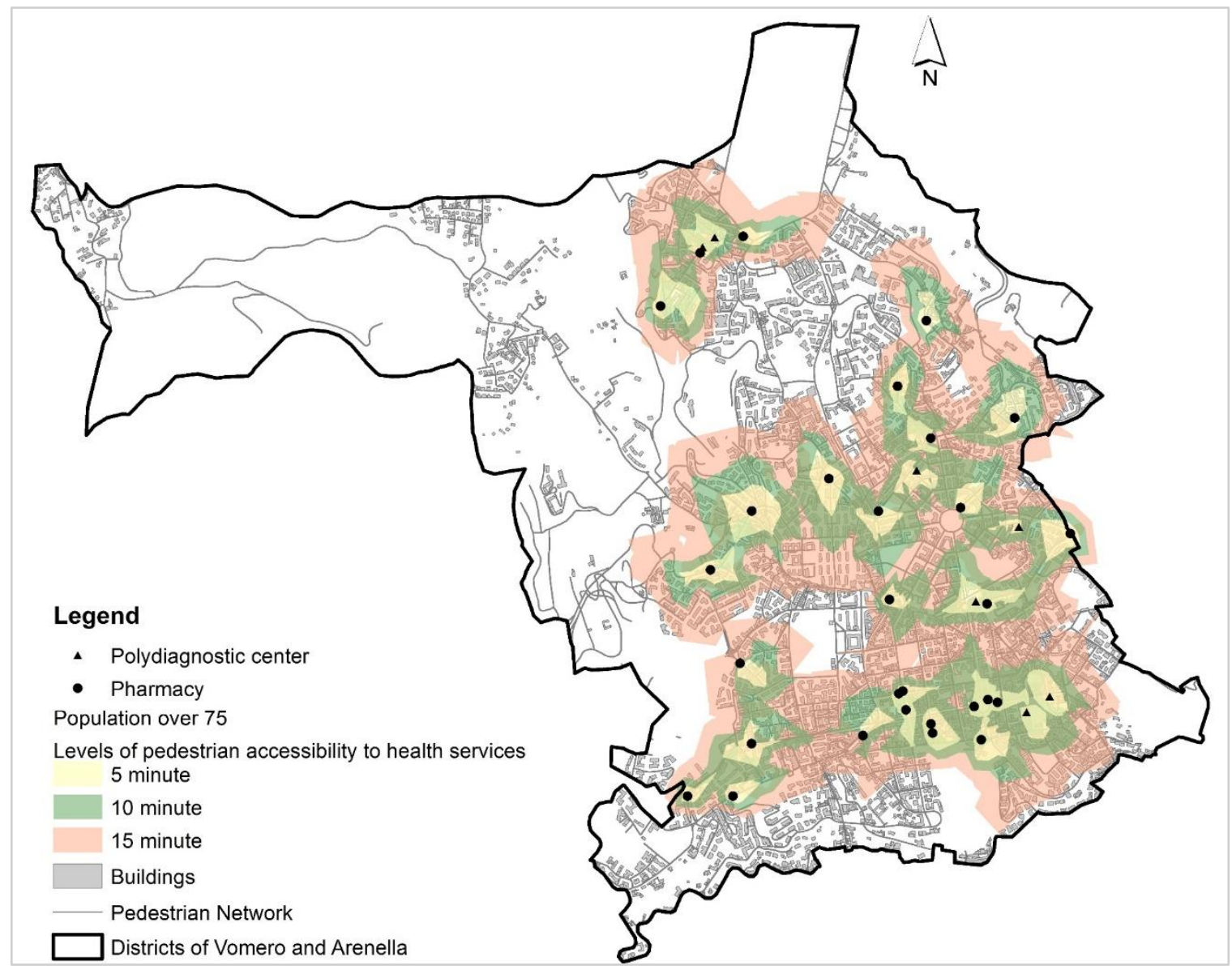


Fig.4 Classification of urban areas in levels of pedestrian accessibility to health services for Naples.

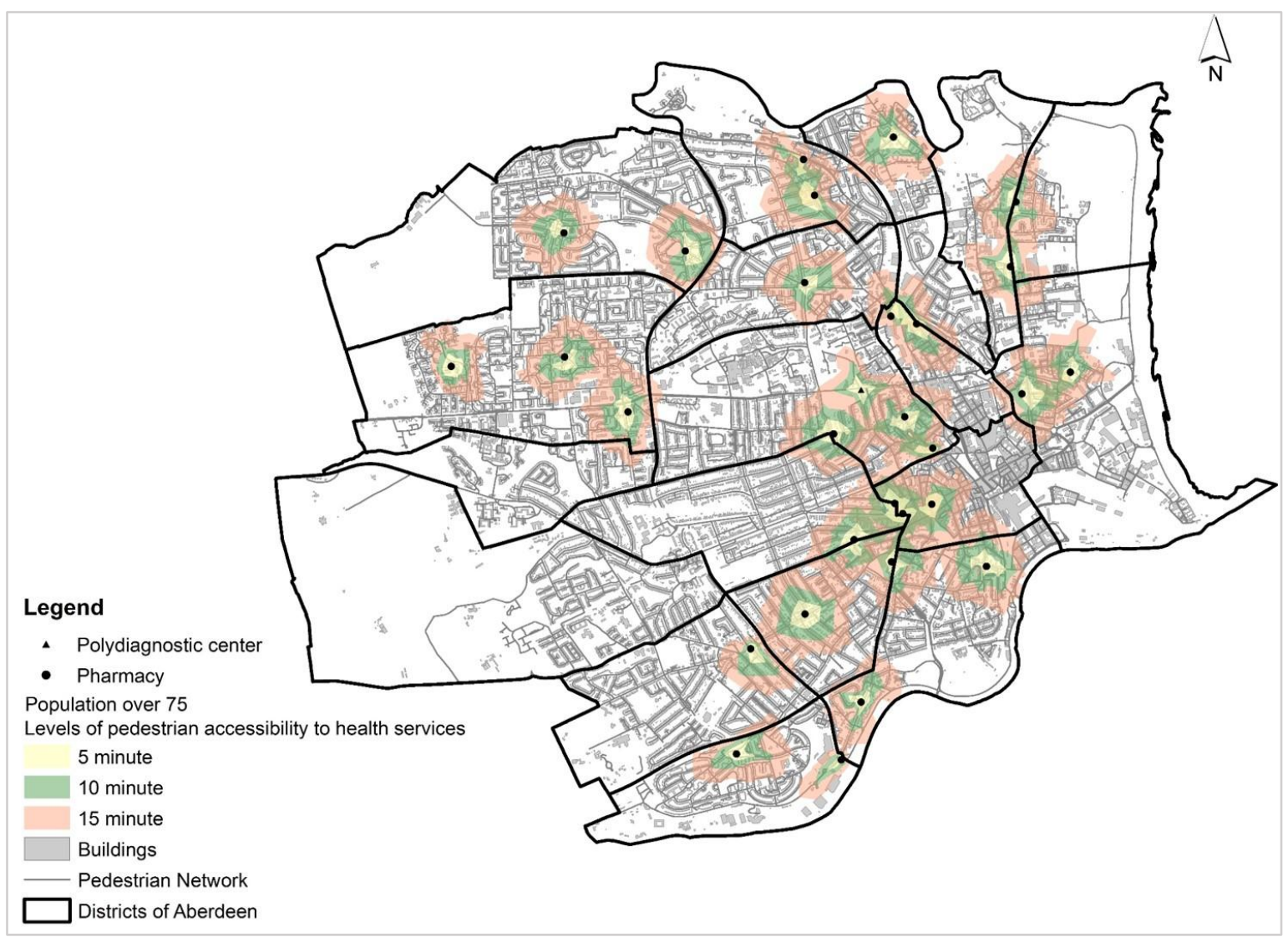

Fig.5 Classification of urban areas in levels of pedestrian accessibility to health services for Aberdeen

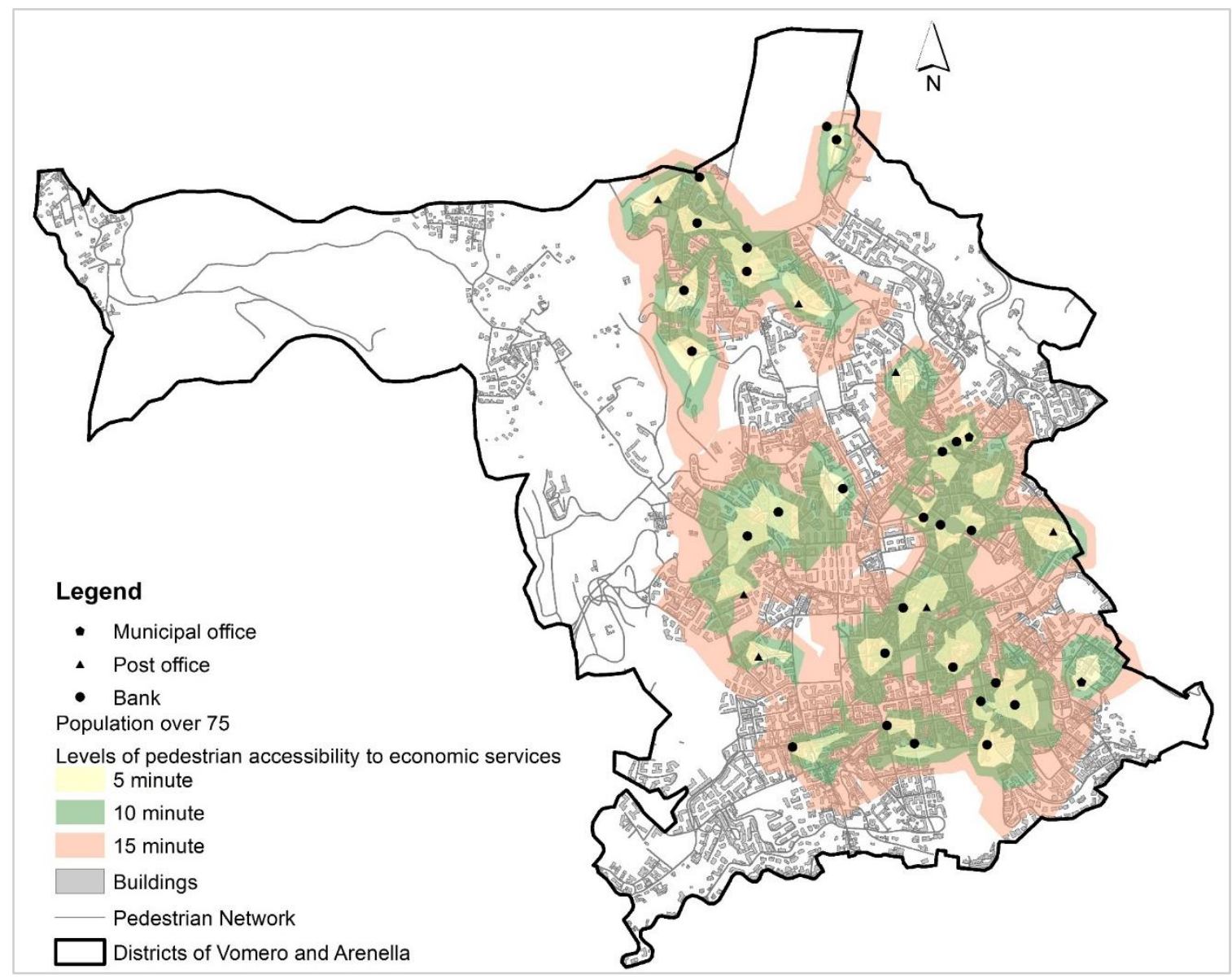


Fig.6 Classification of urban areas in levels of pedestrian accessibility to economic services for Naples

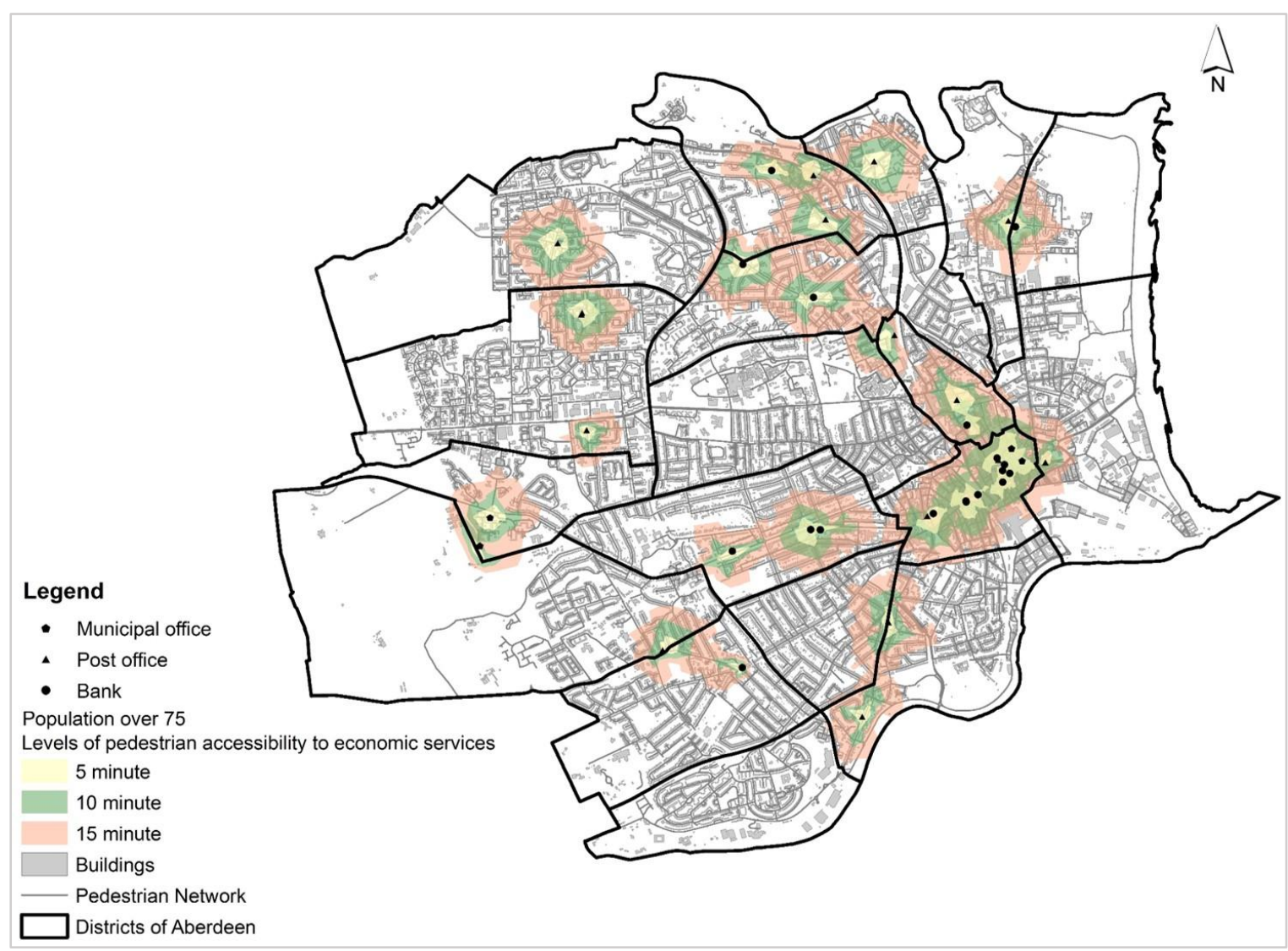

Fig.7 Classification of urban areas in levels of pedestrian accessibility to economic services for Aberdeen

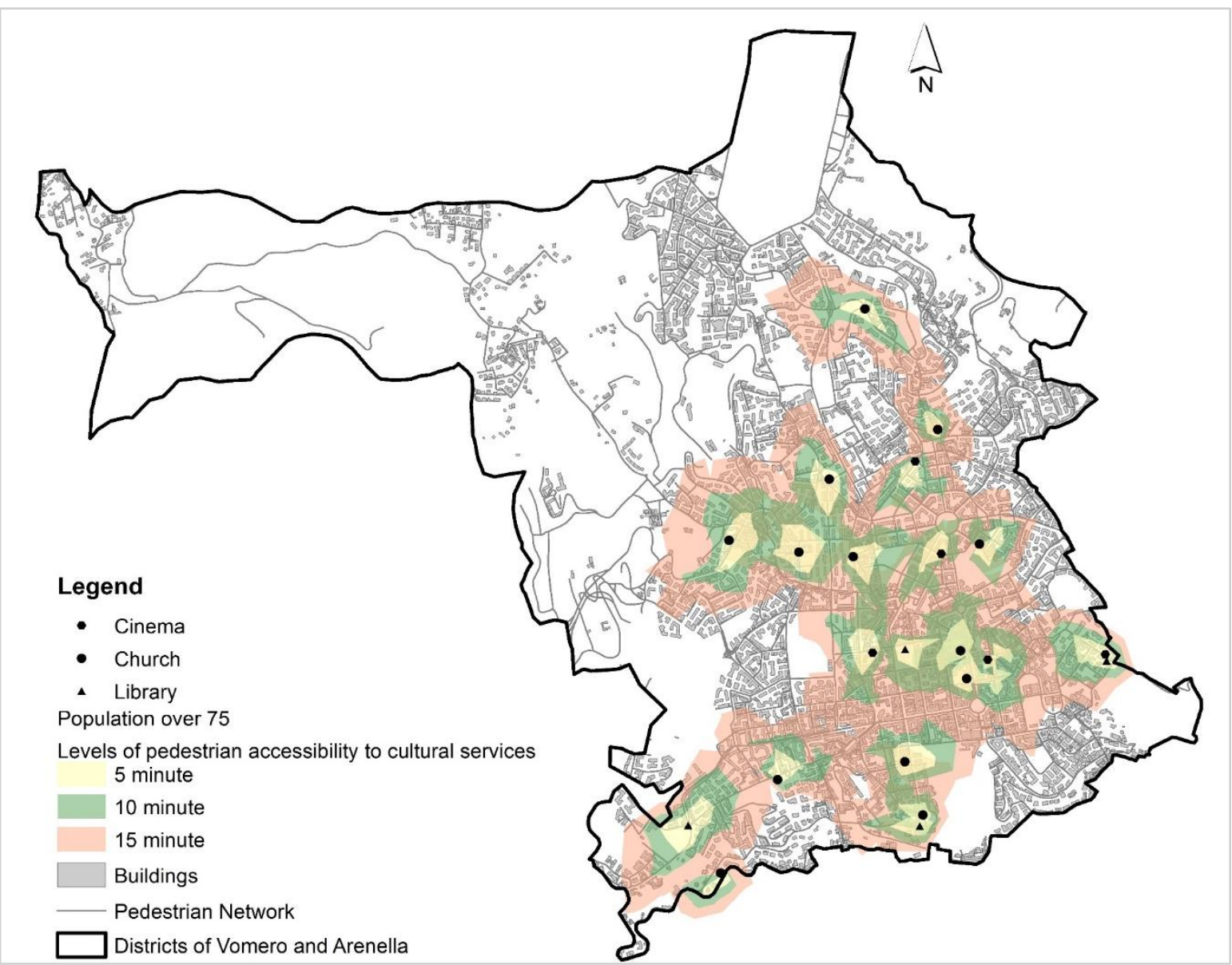


Fig.8 Classification of urban areas in levels of pedestrian accessibility to cultural services for Naples

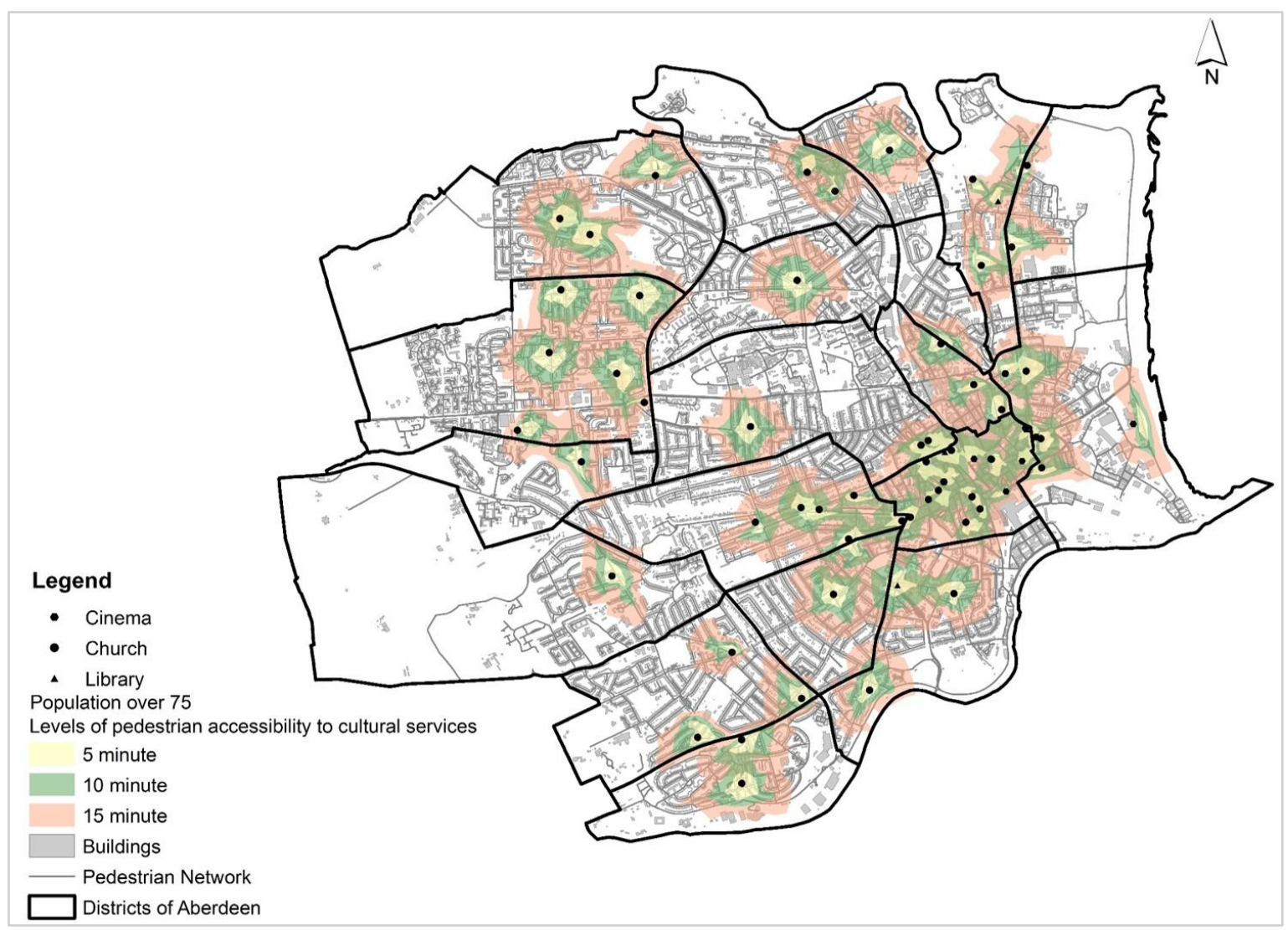

Fig.9 Classification of urban areas in levels of pedestrian accessibility to cultural services for Aberdeen

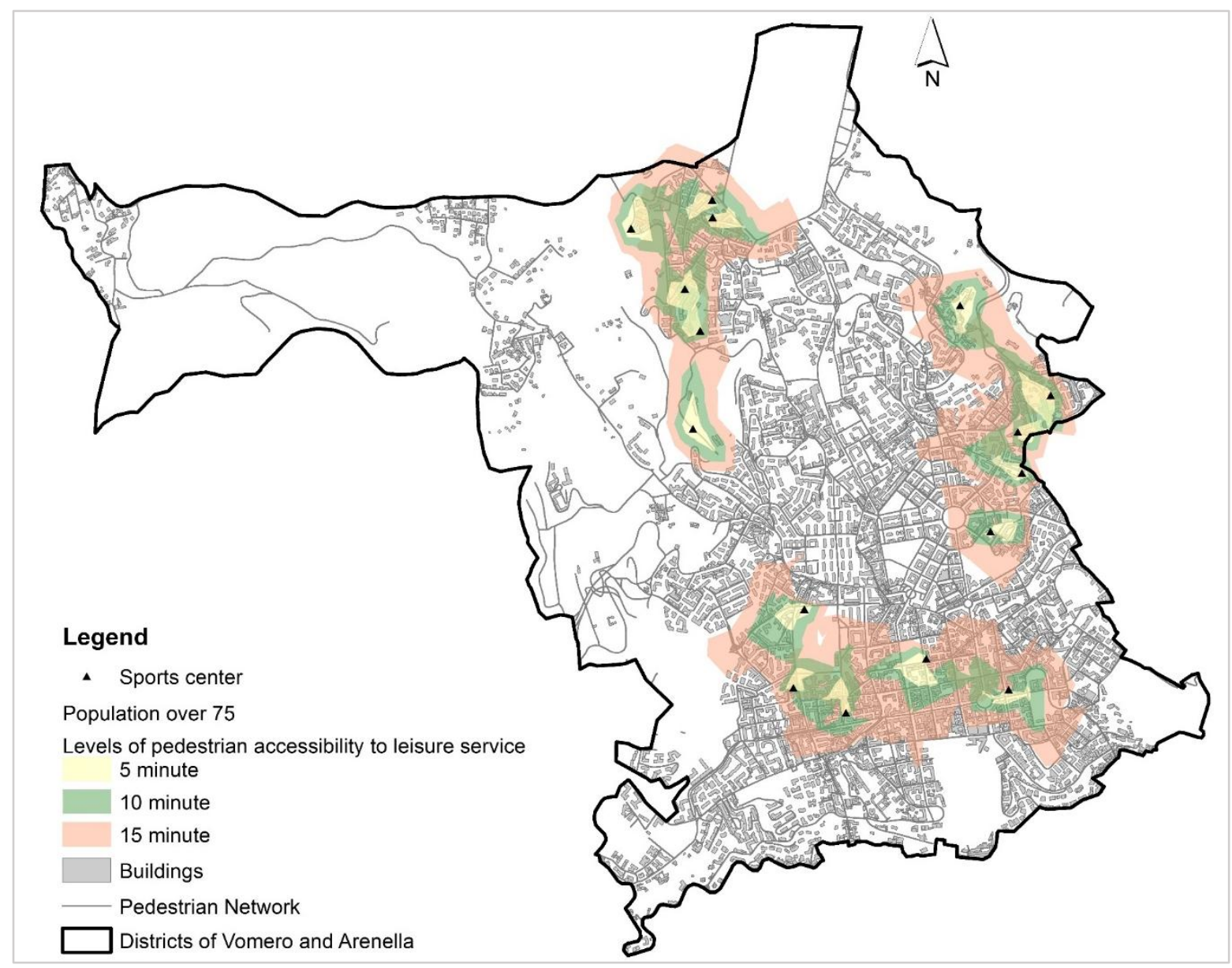


Fig.10 Classification of urban areas in levels of pedestrian accessibility to leisure services for Naples

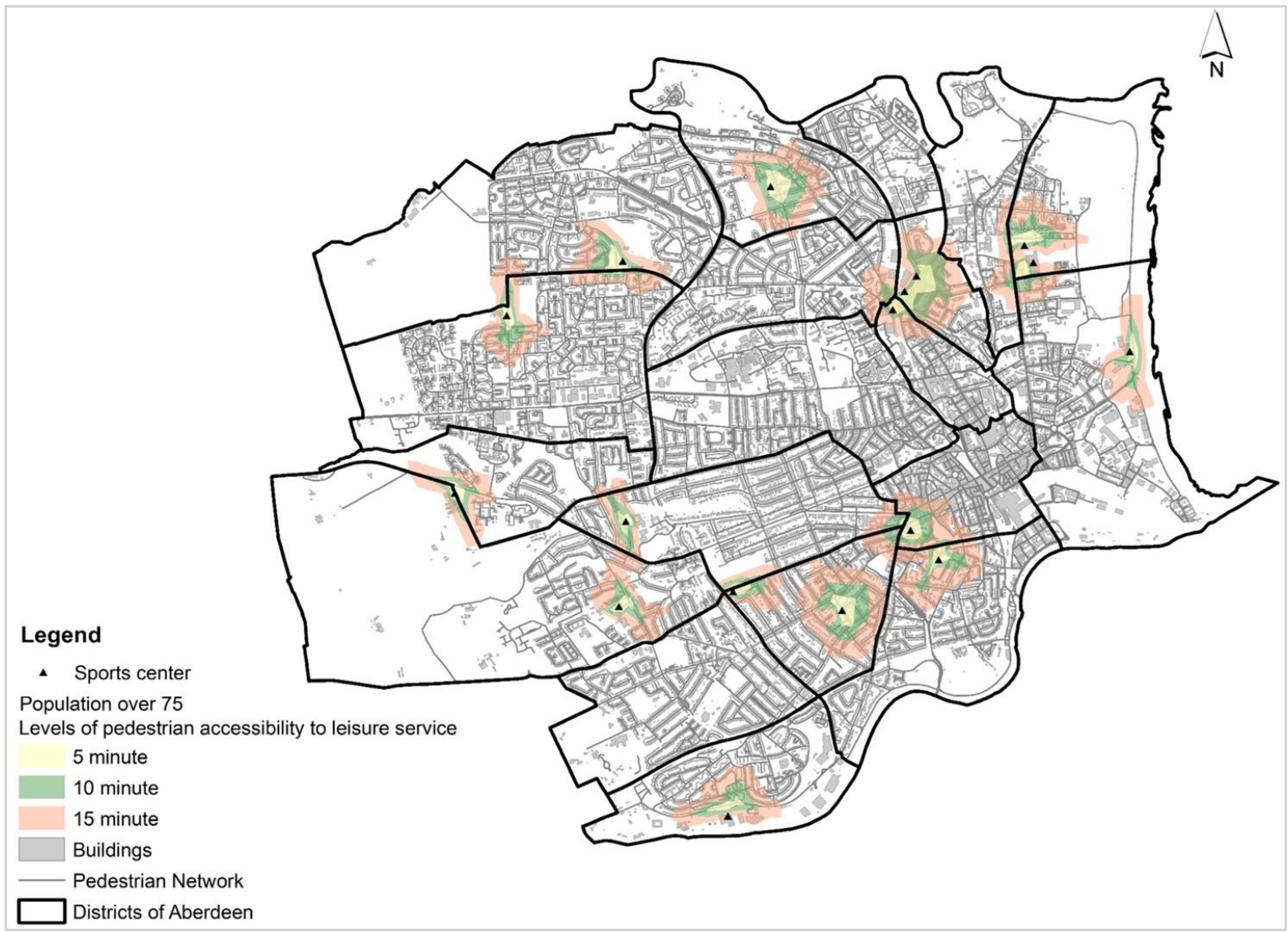

Fig.11 Classification of urban areas in levels of pedestrian accessibility to leisure services for Aberdeen

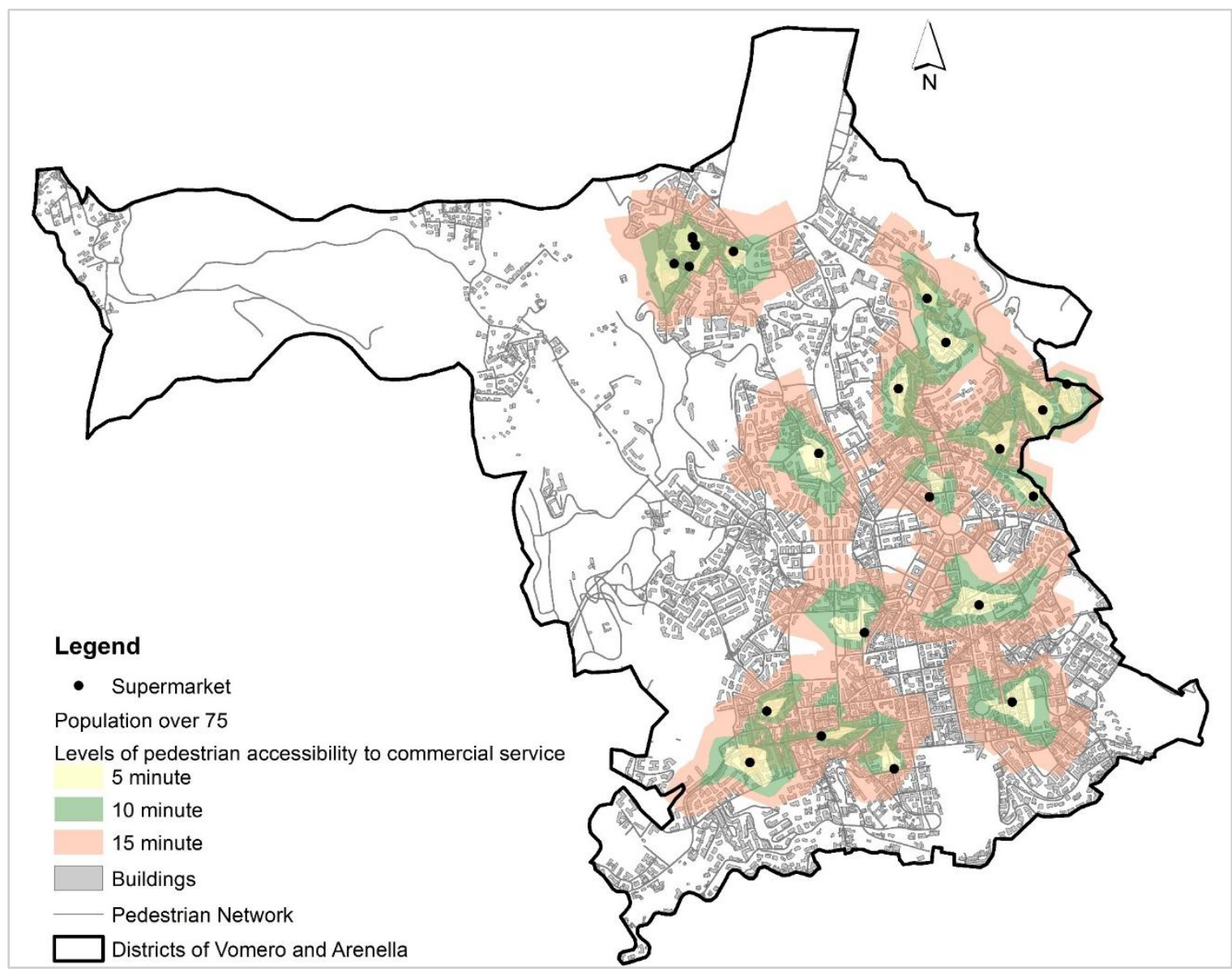




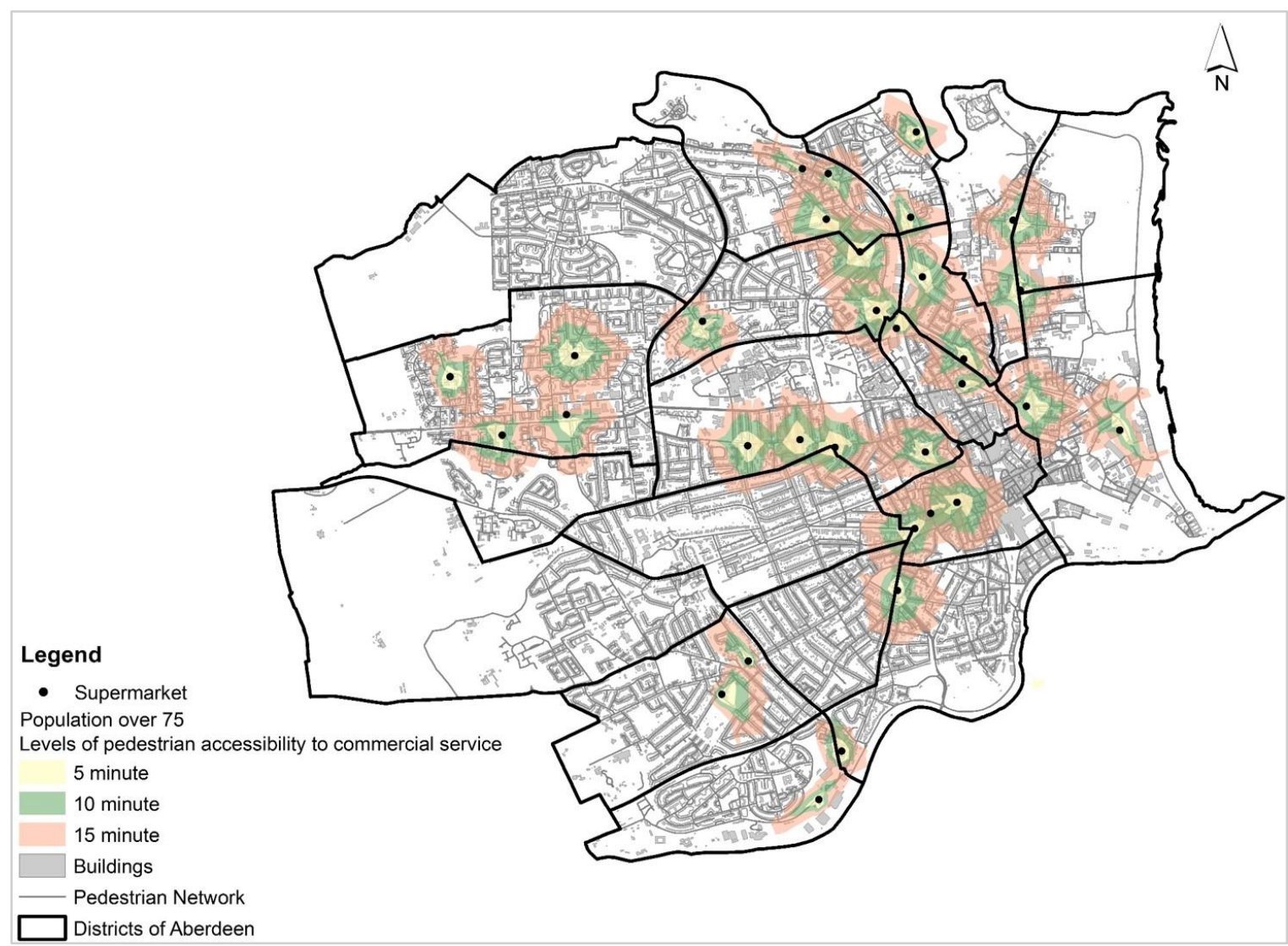

Fig.13 Classification of urban areas in levels of pedestrian accessibility to commercial services for Aberdeen

\section{DISCUSSION OF THE PEDESTRIAN PATHS}

The results obtained by the AHP (section 4) for the two territorial contexts first highlight the importance of physical characteristics. Specifically, the practicability of a pedestrian path aligned, on the one hand, with the conditions of the sidewalks and, on the other, with the obstacles that can limit accessibility to urban services, such as the slope of the sidewalk $>5 \%$ which constitutes a real architectural barrier, in particular for the Neapolitan context, given its hilly conformation. Importance was also allocated to safety features related to protection from various risks during the walking experience, including street lighting, volume of vehicular traffic, and the presence of escalators for both Naples and Aberdeen. Moreover, we considered the importance of the urban context characteristics linked to the pleasantness and attractiveness of the pedestrian path, given, for example, by the presence of urban furniture that improves the degree of comfort of the path. The results obtained from the application also allow one to:

- Identify the portions of the pedestrian network in which to intervene: Interventions may be recommended primarily on the basis of the weights defined by the AHP to improve both the individual characteristics considered and the overall usability and attractiveness (Fig.14). In particular, in the application to the Neapolitan context, it can be noted that the routes in the area of Piazza Vanvitelli and Piazza Medaglie d'Oro are suitable for the elderly, while in the area of Rione Alto and the area of Camaldoli the routes present barriers and obstacles. In Aberdeen, by contrast, all pedestrian paths are suitable for the elderly (Fig.15). These results, in part, are due to the morphological differences of the two cities examined: Naples has a hilly territory while Aberdeen is generally flat (with the exception of the area between the port and the main city centre). For example, Naples demonstrates a higher presence of topographical slopes that may impede the elderly traveller; however, while it exhibits a more sloping territory than the city of Aberdeen, at the same time it also contains a pedestrian network more suitable for the elderly than Aberdeen in terms of network characteristics.

- Identify the "optimal" paths that possess all the qualities (characteristics) considered: For Naples and Aberdeen the coloured areas (green) shown in Figures 14 and 15 are the optimal routes based on individual 
characteristics in their current state, while those remaining are pedestrian paths that need additional development of the tested characteristics to improve their suitability. As shown in Fig. 15, given the significant differences between the two contexts examined, Aberdeen presents a better predisposition of the routes from the point of view of the physical characteristics compared to Naples.

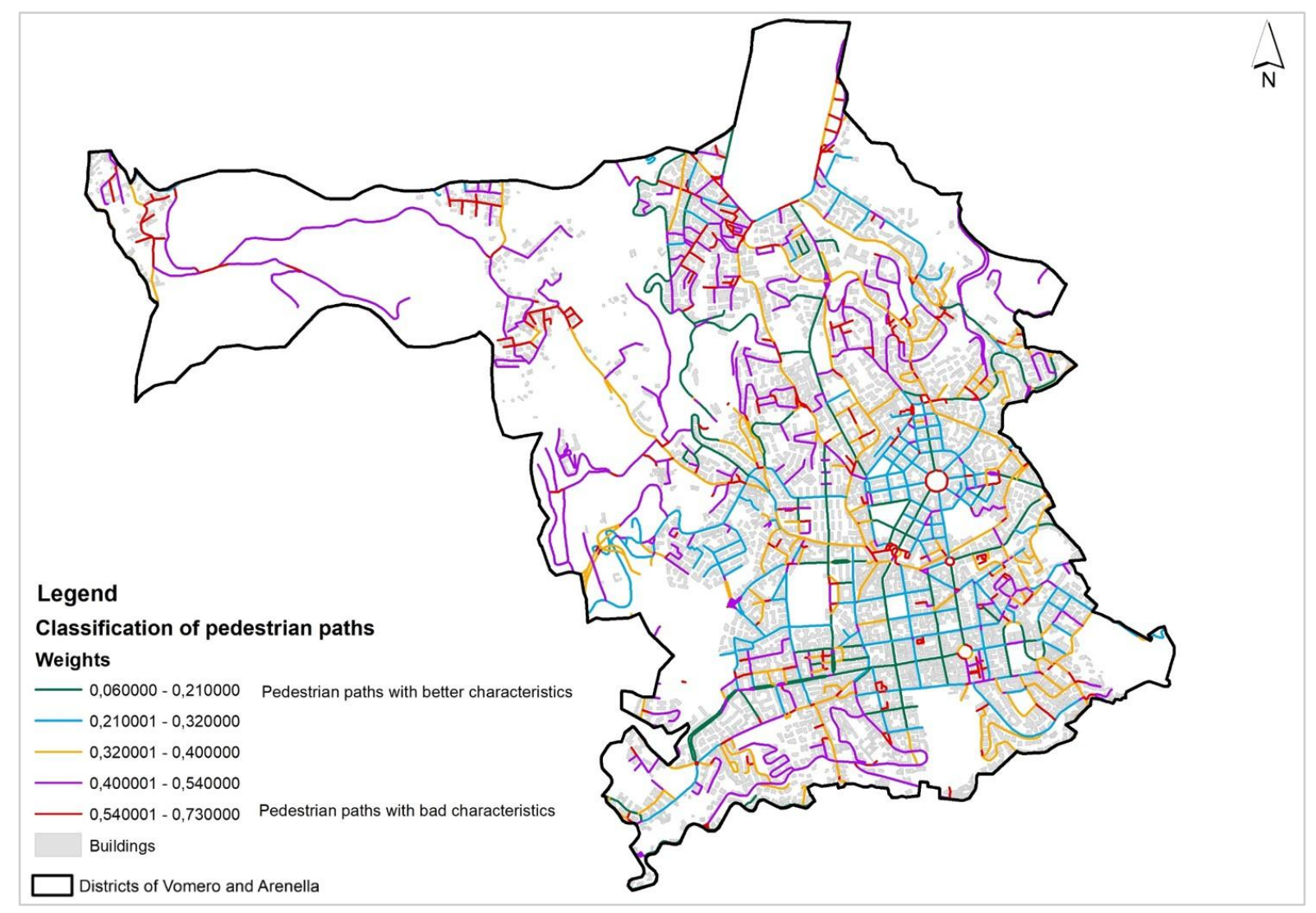

Fig.14 Pedestrian paths classified according to the weights of the characteristics considered for Naples. 


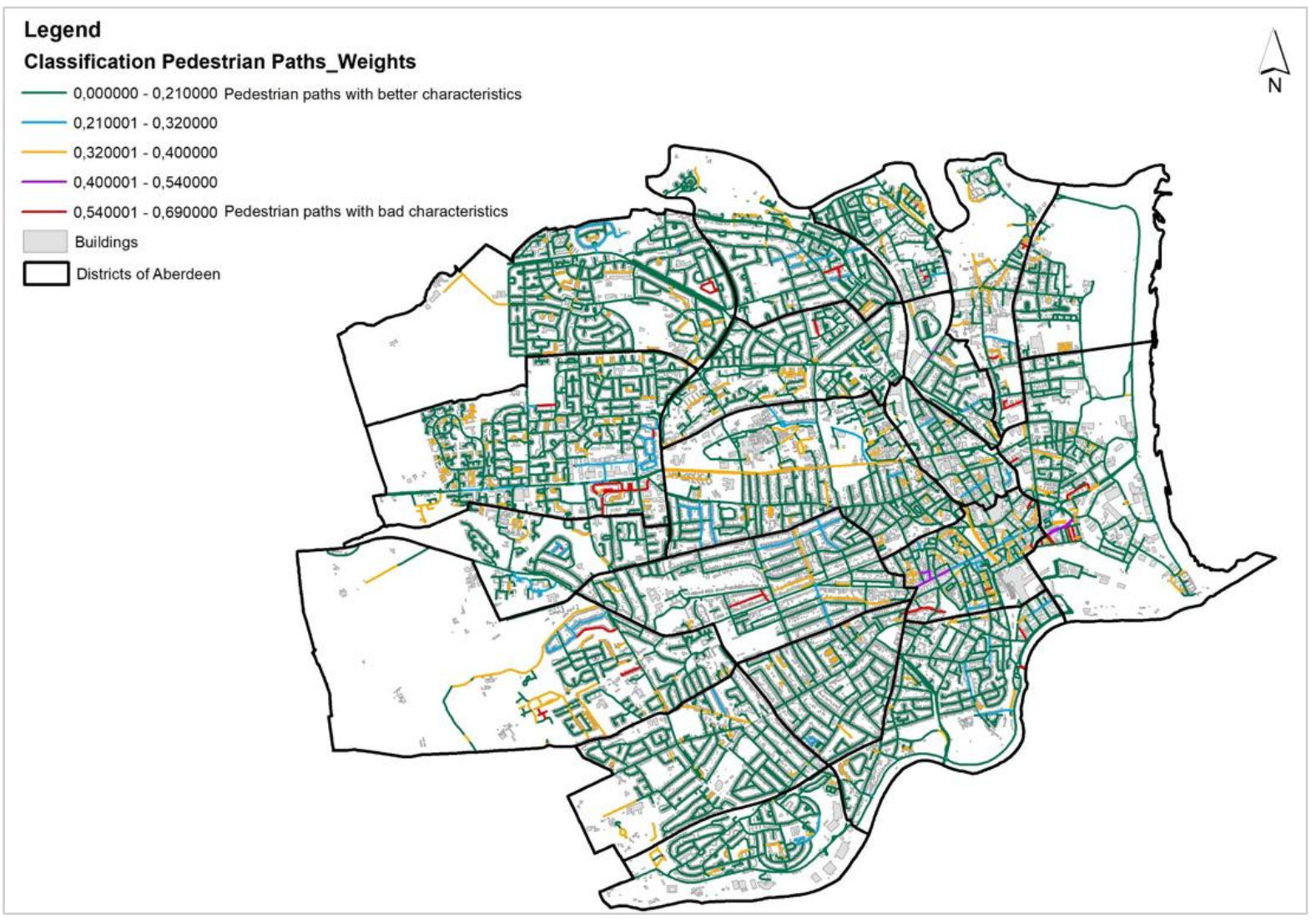

Fig.15 Pedestrian paths classified according to the weights of the characteristics considered for Aberdeen.

\subsection{DISCUSSION OF MEASURE OF PEDESTRIAN ACCESSIBILITY}

In reference to the outputs obtained from the measurement of pedestrian accessibility in relation to the distribution and location of the different types of services of interest to the elderly, the results show that health services (pharmacies, poly-diagnostic centres) are homogeneously distributed and located in those portions of the urban fabric characterised by a unified and planned design, such as in the area bordering the Vomero district and in the area close to the Pascale hospital centre (Arenella district). At the same time, the results present a network of pedestrian paths suitable for the elderly in the Vomero district compared to the area next to the hospital centre and with access to the service in a time interval of 10 minutes. On the other hand, accessibility to health services is lacking in the areas adjacent to the Cardarelli hospital and in the Camaldoli area, which pedestrian network is not suitable for the elderly (fig.4)

For Aberdeen, the offer of health services is widespread in the neighbourhoods of Craigiebuck and Seafield, Queen's Cross and Harlaw, Woodend and Rosemount and Mile End, but access to the service can be reached by the elderly in most districts in 15 minutes, despite the elderly-friendly features of the entire pedestrian network throughout the study area. In some cases, health services are centred along main streets at the borders of districts, which is reflected in longer walking times seen in district centres and on the outskirts of the city (fig.5).

Turning to financial services (banks, post offices and municipal offices), the areas served are concentrated in most of the Vomero and Arenella districts with suitable and accessible routes for the elderly in the area of Piazza Medaglie d'Oro and Vanvitelli in a time interval of 10 minutes, compared to the area of the upper district and the Camaldoli area in which the pedestrian network does not respond to the needs of the elderly. Moreover, for the Camaldoli area there is a total absence of this type of service, while the area of the Rione Alto demonstrates longer times of access to services (fig.6). In contrast, in Aberdeen the areas served by these types of activities exist only in some neighbourhoods, such as the City centre, George Street, Woodside and Hilton, Tillydrone, Queen's Cross and Harlaw and Old Aberdeen, which is the oldest part of the city. In 
the remaining neighbourhoods, there is an absence of this type of service within a 10-minute walk by the elderly population (fig.7).

If the study areas of the Vomero and Arenella districts are generally characterised by medium-high accessibility to health and financial services, those of Aberdeen have better accessibility to health services than financial services.

In the Vomero and Arenella districts, cultural services are concentrated almost exclusively in the area between Piazza Medaglie d'Oro and Vanvitelli with access times to the service in 15 minutes, due to their distribution and location, although with characteristics of an age-friendly pedestrian network (fig. 8). In the districts of Aberdeen there is widespread presence of this type of activity, in particular churches (fig. 9), in contrast to the two districts of Naples and with access times to the service in 10 minutes, which partially responds to the needs and requirements of the over-75 populations.

For both the study areas examined, leisure services (such as sports centres) are lacking. In fact, the areas served for the Vomero and Arenella districts are located only in the area between Piazza Vanvitelli and via Luca Giordano, which is easily accessible for the elderly due to the absence of barriers and obstacles along the pedestrian paths in contrast with the Rione Alto area and east of the Arenella district (fig.10). For Aberdeen, access to recreational services is only in the Woodside and Hilton, City Centre, Old Aberdeen, George Street Garthdee, Ashley and Broomhill districts, while in the other districts these services are not present (fig.11).

The accessibility to commercial services (such as supermarkets) is limited to the adjacent area of the Vomero and Arenella districts, with the difference that in the Vomero district the network of pedestrian paths is more elderly-friendly than the pedestrian network in the Arenella district (fig.12). In Aberdeen, the provision of these services is homogeneous in the study area, with access time generally in 5 and 10 minutes. Only in some neighbourhoods, such as Ferryhill and Queen's Cross and Harwlaw, is the service missing (fig.13).

In the results obtained for the two territorial contexts and for the different types of urban services, we can identify some "hot spots" of functional accessibility. For the fifth municipality of Naples there is high accessibility in the portion of urban fabric integrated between Medaglie d'Oro and Vanvitelli, in correlation also to an adequate pedestrian network, and in the more recently developed areas of via Francesco Solimena and Rione Alto, but with a pedestrian network that does not respond to characteristics suitable for the elderly. The same applies to the city of Aberdeen, where there is a greater offer of services in the areas of the City Centre and George Street following the 1970s redevelopment due to the proximity to the port. The concentration of the elderly in areas characterised by high accessibility is reflective of the importance of such characteristics for older urban residents. This finding, in turn, offers a valuable contribution to practices in urban planning and the consideration of the values of residents. In fact, the functional offer is diversified in these areas by accessibility advantages offered, due to the availability of multiple options, while in newly formed areas it has led to "uneven" access to services both for the Neapolitan context and for the city of Aberdeen.

\section{CONCLUSIONS}

This research work constitutes a first tool to support decision makers in the development of policies aimed at improving pedestrian accessibility to urban services, in order to increase the quality of life of the elderly population and allow them to play an active role in the life of the community.

The methodological results of this work aim to integrate and overcome the demonstrated research gap in terms of scale, and to enhance approaches on the issue of accessibility to urban areas for the elderly. This is realised by relating the behaviour of the elderly in terms of walking speed and the characteristics of the physical pedestrian network to the characteristics of safety and the urban context through a new measure of pedestrian accessibility combined with the offer of urban services. The methodological approach used allows quantification of the definition of the levels of accessibility to the different types of urban services. 
The operational results, obtained by using innovative research tools, show the portions of the municipal area where intervention is needed, and how to intervene most effectively. The accessibility levels also identify the critical areas that require priority interventions and the areas where it is possible to increase the levels of pedestrian accessibility to urban services. For example, the urban portions characterised by a lack of accessibility to urban services require both "punctual" interventions, related to a better distribution and localisation of services, and "areal" interventions, linked to the urban context. By contrast, urban areas with a high supply of service areas but with pedestrian barriers and obstacles require "linear" interventions to improve the walking experience of the elderly. Therefore, integrated actions should be taken on both the functional and physical subsystems to improve and increase accessibility to urban areas for the elderly and reduce their social exclusion.

The range of possible effective solutions to improve the structure and organisation of the territory can be included, as regards the network of pedestrian routes, within the urban plans of sustainable mobility, while interventions for the improvement of distribution services can be envisaged within the service plans and implemented by public administrations, in order to improve the quality of life of populations over 75 . The precise definition of the different types of interventions represents the future development of research.

It is, however, important to acknowledge some limitations of the study. Firstly, the choice of the pedestrian network variables considered was somewhat constrained due to the availability of relevant data. In particular, identifying datasets at the local level that provided precise, comprehensive information that could be associated with each link of the pedestrian network proved challenging, particularly for those attributes related to the sense of security and urban context for the elderly. This also impacted upon the weights attributed to each variable of the pedestrian network within the measure of pedestrian accessibility. Secondly, in the measure of pedestrian accessibility, the choices of routes by the elderly are not considered. These are constraints that warrant additional attention in future research.

\section{AUTHOR CONTRIBUTIONS}

Although this paper should be considered a result of the common work of the authors, F. Gaglione, C. Cottrill and C. Gargiulo for the section 1; F. Gaglione for the section 2;2.1;2.2;2.3 and 3; C. Cottrill for the section 4; F. Gaglione for the section 4.1; C. Gargiulo for the section 5; F. Gaglione for the section 5.1; C. Gargiulo for the section 6

\section{REFERENCES}

Ahmad, Z., Batool, Z., \& Starkey, P. (2019). Understanding mobility characteristics and needs of older persons in urban Pakistan with respect to use of public transport and self-driving. Journal of Transport Geography, 74, 181-190. doi: https://doi.org/10.1016/j.jtrangeo.2018.11.015

Battarra, R. Zucaro, F., Tremiterra, MR (2018) Smart Mobility and Elderly People. Can ICT Make the City more accessible for everybody? TeMA. Journal of Land Use, Mobility and Environment, Special Issue 2, oct. 2018, ISSN 1970-987.doi: https://doi.org/10.6092/1970-9870/5768

Bivina, G. R., \& Parida, M. (2019). Prioritizing pedestrian needs using a multi-criteria decision approach for a sustainable built environment in the Indian context. Environment, Development and Sustainability, 1-22. doi: https://doi.org/10.1007/s10668-019-00381-w

Borst, H. C., Miedema, H. M., de Vries, S. I., Graham, J. M., \& van Dongen, J. E. (2008). Relationships between street characteristics and perceived attractiveness for walking reported by elderly people. Journal of Environmental Psychology, 28(4), 353-361. doi: https://doi.org/10.1016/j.jenvp.2008.02.010 
Bricocoli, M. Bouwer, Aleid E., Gargiulo, C (2018), Editorial Preface: Elderly Mobility, TeMA. Journal of Land Use, Mobility and Environment, Special Issue 2, p. 3-8, oct. 2018. ISSN 1970-9870.doi: http://dx.doi.org/10.6092/1970-9870/5868

Broome K., Worrall L., Fleming J. \& Boldy, D. (2012). Evaluation of flexible route bus transport for older people. Transport Policy, 21, 85-91. doi: https://doi.org/10.1016/j.tranpol.2012.02.005

Cerin, E., Mellecker, R., Macfarlane, D. J., Barnett, A., Cheung, M. C., Sit, C. H., \& Chan, W. M. (2013). Socioeconomic status, neighborhood characteristics, and walking within the neighborhood among older Hong Kong Chinese. Journal of aging and health, 25(8), 1425-1444. doi: https://doi.org/10.1177/0898264313510034

Cheng, L., Chen, X., Yang, S., Cao, Z., De Vos, J., \& Witlox, F. (2019). Active travel for active ageing in China: The role of built environment. Journal of transport geography,76, 142-152. doi: https://doi.org/10.1016/j.jtrangeo.2019.03.010

Colclough, J. G. (2009). Modelling Pedestrian Accessibility Using GIS Techniques to Assess Development Sustainability. In European Transport Conference.

Cottrill C., Gaglione F., Gargiulo C.\& Zucaro F. (2019). Defining the characteristics of walking paths to promote an active ageing. CRC Press, 2019.In press

Currie, G., Richardson, T., Smyth, P., Vella-Brodrick, D., Hine, J., Lucas, K., ... \& Stanley, J. (2010). Investigating links between transport disadvantage, social exclusion and well-being in Melbourne-Updated results. Research in transportation economics, 29(1), 287-295. doi: https://doi.org/10.1016/j.retrec.2010.07.036

Furukawa, H., \& Wang, Z. (2019, March). A Route Evaluation Method Considering the Subjective Evaluation on Walkability, Safety, and Pleasantness by Elderly Pedestrians. In International Conference on E-Business and Telecommunications (pp. 408-416). Springer, Cham. doi: https://doi.org/10.1007/978-3-03024322-7_51

Gaglione F., Gargiulo C.\& Zucaro F. (2019). Elders' quality of life and urban accessibility. A method proposal for spatial planning". TeMA. Journal of Land Use, Mobility and Environment. doi: https://doi.org/10.6092/1970-9870/6272

Gargiulo, C, Zucaro, F., Gaglione, F. (2018), A set of variables for elderly accessibility in urban areas, TeMA. Journal of Land Use, Mobility and Environment, Special Issue 2, p. 53-66, oct. 2018, ISSN 1970-987 doi: http://dx.doi.org/10.6092/1970-9870/5738

Gargiulo, C., Zucaro F. \& Gaglione, F. (2019), Improving accessibility to urban services for over 65: a GISsupported method, in C. Gargiulo \& C. Zoppi (Eds.), Planning, nature and ecosystem services (pp. 839-850). Naples: FedOAPress. ISBN: 978-88-6887-054-6, doi: 10.6093/978-88-6887-054-6

Gharaveis, A. (2020). A systematic framework for understanding environmental design influences on physical activity in the elderly population. Facilities. doi: https://doi.org/10.1108/F-08-2018-0094

Guagliardo, M.F. (2004). Spatial accessibility of primary care: concepts, methods and challenges. International Journal of Health Geographics, 3. doi: https://doi.org/10.1186/1476-072X-3-3

Haustein, S. (2012). Mobility behavior of the elderly: an attitude-based segmentation approach for a heterogeneous target group. Transportation, 39(6), 1079-1103. doi: https://doi.org/10.1007/s11116-0119380-7

Joe Weber \& Mei-Po Kwan (2002) Bringing Time Back In: A Study on the Influence of Travel Time Variations and Facility Opening Hours on Individual Accessibility, The Professional Geographer, 54:2, 226240. doi: https://doi.org/10.1111/0033-0124.00328

Joo, Y. J., \& Kim, S. H. (2011). A new route guidance method considering pedestrian level of service using multi-criteria decision making technique. 한국공간정보학회지, 19(1), 83-91. 
Kim, M. J., Seo, S. H., Seo, A. R., Kim, B. K., Lee, G. Y., Choi, Y. S., ... \& Park, K. S. (2019). The Association of Perceived Neighborhood Walkability and Environmental Pollution with Frailty Among Community-dwelling Older Adults in Korean Rural Areas: A Cross-sectional Study. Journal of Preventive Medicine and Public Health, 52(6), 405. doi: https://doi.org/10.3961/jpmph.19.166

Kim, S., Park, S., \& Lee, J. S. (2014). Meso-or micro-scale? Environmental factors influencing pedestrian satisfaction. Transportation Research Part D: Transport and Environment, 30, 10-20. doi: https://doi.org/10.1016/j.trd.2014.05.005

Kotval, K. Z. (2017). Transit accessibility for older adults in the Greater Lansing, Michigan region, Quality in Ageing and Older Adults, 18(3), 175-187. doi: https://doi.org/10.1108/QAOA-08-2016-0032

Langford, M., Higgs, G., \& Fry, R. (2012). Using floating catchment analysis (FCA) techniques to examine intra-urban variations in accessibility to public transport opportunities: the example of Cardiff, Wales. Journal of Transport Geography, 25, 1-14. doi: https://doi.org/10.1016/j.jtrangeo.2012.06.014

Lee, H. S., \& Park, E. Y. (2014). Comparing the environment for elderly pedestrians among different-sized cities of Gyeonggi province in Korea. International Journal of Urban Sciences, 18(1), 76-89. doi: https://doi.org/10.1080/12265934.2013.863449

Li, F., Fisher, K. J., Brownson, R. C., \& Bosworth, M. (2005). Multilevel modelling of built environment characteristics related to neighbourhood walking activity in older adults. Journal of Epidemiology \& Community Health, 59(7), 558-564. doi: http://dx.doi.org/10.1136/jech.2004.028399

Lin, T. G., Xia, J. C., Robinson, T. P., Goulias, K. G., Church, R. L., Olaru, D., ... \& Han, R. (2014). Spatial analysis of access to and accessibility surrounding train stations: A case study of accessibility for the elderly in Perth, Western Australia. Journal of Transport Geography, 39, 111-120. doi: https://doi.org/10.1016/j.jtrangeo.2014.06.022

Loo, B. P., \& Lam, W. W. Y. (2012). Geographic accessibility around health care facilities for elderly residents in Hong Kong: A microscale walkability assessment. Environment and Planning B: Planning and Design, 39(4), 629-646. doi: https://doi.org/10.1068/b36146

Luo, W., \& Wang, F. (2003). Measures of spatial accessibility to health care in a GIS environment: synthesis and a case study in the Chicago region. Environment and Planning B: Planning and Design, 30(6), 865-884. doi:https://doi.org/10.1068/b29120

Lovett, A., Haynes, R., Sünnenberg, G., \& Gale, S. (2002). Car travel time and accessibility by bus to general practitioner services: a study using patient registers and GIS. Social science \& medicine, 55(1), $97-$ 111. doi: https://doi.org/10.1016/S0277-9536(01)00212-X

Lucas, K., Van Wee, B., and Maat, K., 2016. A method to evaluate equitable accessibility. Transportation, 43, 473-490. doi:https://doi.org/10.1007/s11116-015-9585-2

Manaugh, K., \& El-Geneidy, A. (2011). Validating walkability indices: How do different households respond to the walkability of their neighborhood? Transportation research part D: transport and environment, 16(4), 309-315. doi: https://doi.org/10.1016/j.trd.2011.01.009

Marquet, O., Hipp, J. A., \& Miralles-Guasch, C. (2017). Neighborhood walkability and active ageing: a difference in differences assessment of active transportation over ten years. Journal of Transport \& Health, 7, 190-201. doi: https://doi.org/10.1016/j.jth.2017.09.006

McGrail, M. R., \& Humphreys, J. S. (2014). Measuring spatial accessibility to primary health care services: Utilising dynamic catchment sizes. Applied Geography, 54, 182-188. doi: https://doi.org/10.1016/j.apgeog.2014.08.005

Moon, M., Lee, Y., Yu, K., \& Kim, J. (2016). Optimized Path Finding Algorithm for Walking Convenience of the People with Reduced Mobility. Journal of the Korean Society of Surveying, Geodesy, Photogrammetry and Cartography, 34(3), 273-282. doi: https://doi.org/10.7848/ksgpc.2016.34.3.273 
Oswald Beiler, M. R., \& Phillips, B. (2015). Prioritizing pedestrian corridors using walkability performance metrics and decision analysis. Journal of Urban Planning and Development, 142(1), 04015009. doi: https://doi.org/10.1061/(ASCE)UP.1943-5444.0000290

Papa R., Fistola R., Gargiulo C. (2018) (eds) Smart Planning: Sustainability and Mobility in the Age of Change. Green Energy and Technology. Springer, Cham, ISSN 1865-3537 Green Energy and Technology book series

Riley, D. L., Mark, A. E., Kristjansson, E., Sawada, M. C., \& Reid, R. D. (2013). Neighborhood walkability and physical activity among family members of people with heart disease who participated in a randomized controlled trial of a behavioral risk reduction intervention. Health \& place, 21, 148-155. doi: https://doi.org/10.1016/j.healthplace.2013.01.010

Saaty, T. L. (1980). The Analytic Hierarchy Process Mcgraw Hill, New York. AGRICULTURAL ECONOMICS REVIEW, 70.

Saaty, T. L., \& Vargas, L. G. (2012). Models, methods, concepts \& applications of the analytic hierarchy process (Vol. 175). Springer Science \& Business Media. ISBN 978-1-4614-3597-6

Sayyadi, G., \& Awasthi, A. (2013). AHP-based approach for location planning of pedestrian zones: Application in Montréal, Canada. Journal of transportation engineering, 139(2), 239-246. doi: https://doi.org/10.1061/(ASCE)TE.1943-5436.0000493

Shao, F., Sui, Y., Yu, X., \& Sun, R. (2019). Spatial-temporal travel patterns of elderly people-A comparative study based on buses usage in Qingdao, China. Journal of Transport Geography, 76, 178-190. doi: https://doi.org/10.1016/j.jtrangeo.2019.04.001

Szeto, W. Y., Yang, L., Wong, R. C. P., Li, Y. C., \& Wong, S. C. (2017). Spatio-temporal travel characteristics of the elderly in an ageing society. Travel Behaviour and Society, 9, 10-20. doi: https://doi.org/10.1016/j.tbs.2017.07.005

Tao, Z., \& Cheng, Y. (2019). Modelling the spatial accessibility of the elderly to healthcare services in Beijing, China. Environment and Planning B: Urban Analytics and City Science, 46(6), 1132-1147. doi: https://doi.org/10.1177/2399808318755145

Wang, F. (2012). Measurement, optimization, and impact of health care accessibility: a methodological review. Annals of the Association of American Geographers, 102(5), 1104-1112. doi: https://doi.org/10.1080/00045608.2012.657146

Weber, D. (2016). Differences in physical aging measured by walking speed: evidence from the English Longitudinal Study of Ageing. BMC geriatrics, 16(1), 31. doi: https://doi.org/10.1186/s12877-016-0201-x

Wey, W. M., \& Chiu, Y. H. (2013). Assessing the walkability of pedestrian environment under the transitoriented development. Habitat International, 38, 106-118. doi: https://doi.org/10.1016/j.habitatint.2012.05.004

Wong, R. C. P., Szeto, W. Y., Yang, L., Li, Y. C., \& Wong, S. C. (2017). Elderly users' level of satisfaction with public transport services in a high-density and transit-oriented city. Journal of Transport \& Health, 7 , 209-217. doi: https://doi.org/10.1016/j.jth.2017.10.004

World Health Organization (2015), "World Report of ageing and health", available at: http://apps.who.int/iris/bitstream/10665/186463/1/9789240694811_eng.pdf (accessed 8 September 2017)

Yang, D. H., Goerge, R., \& Mullner, R. (2006). Comparing GIS-based methods of measuring spatial accessibility to health services. Journal of medical systems, 30(1), 23-32. doi: https://doi.org/10.1007/s10916-006-7400-5. 